\title{
No SÓlO CUERPOS: LA CULTURA MATERIAL EXHUMADA DE LAS FOSAS DEL FRANQUISMO EN PATERNA
}

\section{Not just bodies: material culture documented in the mass graves from Francoism repression in Paterna}

\section{ANDREA MORENO MARTÍN ${ }^{1}$, MIGUEL MEZQUIDA FERNÁNDEZ², ELOY ARIZA JIMÉNEZ³}

(1) andrea.moreno@uv.es

(2) arqueoantro@gmail.com

(3) eloyariza@gmail.com

\section{Resumen:}

Este artículo pretende destacar cómo, desde la arqueología forense, se puede abordar el análisis de las prácticas de represión y violencia política sobre la población civil y, al mismo tiempo, estudiar a las víctimas y el contexto de sus asesinatos desde un enfoque social. Para abordar este reto partimos de la cultura material documentada en las fosas del cementerio municipal de Paterna (Valencia) como ejemplo paradigmático en las exhumaciones de víctimas del franquismo del territorio valenciano. A partir de esta materialidad nos planteamos algunas cuestiones sobre el futuro de los objetos asociados a las víctimas que se recuperan en las fosas comunes y, especialmente, reflexionamos sobre estos objetos exhumados, pues dadas las casuísticas y los escenarios jurídicos y procedimentales en los que se ven inmersos, permanecen a menudo en un limbo patrimonial y jurídico.

Palabras clave: arqueología forense, franquismo, exhumaciones, cultura material, memoria pública.

\section{Abstract:}

This article aims to highlight how, from forensic archeology, one can approach the analysis of the practices of repression and political violence against the civilian population and, at the same time, study the victims and the context of their murders from a social perspective. To address this challenge, we review some material culture documented in the mass graves of the Paterna cemetery (Valencia) as a paradigmatic example of the exhumations of Franco's dictatorship victims in Valencian territory. Based on this materiality, we argue some questions about the future of these objects associated with the victims which are recovered in mass graves and, especially, we analyse these exhumed objects, because given the casuistry and the legal and procedural scenarios in which they are immersed, its management often remains in a patrimonial and legal limbo.

Key words: forensic archeology, Francoism, exhumations, material culture, public memory.

Copyright: (C) 2021 Andrea Moreno et al. This is an open access paper distributed under the terms 
Cuando las autoridades temporales y espirituales han puesto una categoría de seres humanos fuera de aquellos cuya vida tiene un precio, no hay nada más natural para el hombre que matar. Cuando se sabe que es posible matar sin arriesgarse a un castigo ni reprobación, se mata; o al menos se rodea de sonrisas alentadoras a aquellos que matan.

Simone Weil

\section{INTRODUCCIÓN}

La arqueología es una disciplina que se ha consolidado como una ciencia donde los planteamientos monolíticos han sido marginados y donde los temas y objetos de estudio no se acotan únicamente al pasado remoto o clásico. Muy al contrario, tanto los enfoques multitemporales y diacrónicos como la interdisciplinariedad se han tornado pilares básicos de nuestro trabajo (Johnson 2000; Buchli y Lucas 2001; Vicent 2007; Criado 2010; Hamilakis 2011; Hodder 2012a y 2012b; Harris y Cipolla 2017; Theune 2018). En la actualidad, aunque convivimos con paradigmas hegemónicos, trabajamos -o eso se pretende- partiendo de enfoques donde la arqueología dialoga con otras disciplinas, donde las teorías antropológicas y filosóficas también nos ayudan a la hora de formular nuestras tesis, y donde la cronología no sesga nuestros intereses, pues el pasado reciente también es susceptible de ser estudiado y analizado bajo la óptica arqueológica (González-Ruibal 2008; Schofield 2010; Harrison y Schofield 2010; González-Ruibal 2012; Sturdy 2015; Renshaw 2018; GonzálezRuibal 2019). Precisamente, este rasgo de la arqueología se torna en una de las piedras angulares de la arqueología forense. Y lo es, especialmente, cuando abordamos proyectos arqueo-antropológicos para la localización, exhumación e identificación de víctimas de represión y violencia política durante la guerra civil y la dictadura franquista. Huelga decir, que la arqueología forense -la arqueología del conflicto (González-Ruibal 2007; Gassiot 2008; Mezquida 2013) o arqueología del desastre al referirse a crímenes masivos y vulneración de derechos humanos (Gould 2007)- incide tanto en la dimensión histórico-política como en la dimensión jurídica de la violencia sobre las víctimas; y sigue la premisa de hacer justicia no consiste sólo en castigar al culpable, sino también en adoptar la perspectiva de las víctimas (Mate 2011: 5-6).

Complementariamente a la investigación documental y la memoria oral, son precisamente las exhumaciones y los estudios y análisis que llevan aparejados, los que aportan luz y confirman de una manera científica y empírica muy evidente, prácticas de violencia premeditada, de masacres coordinadas y de represión estandarizada por parte del Estado franquista. El estudio estratigráfico de las fosas, el análisis osteoarqueológico de los restos humanos y la interpretación y documentación de las evidencias materiales asociadas permiten recuperar a las víctimas y, además, repensar desde el presente una historia reciente que se construyó ignorando esas memorias y sus historias. Y es que, aunque otras disciplinas como la historia, la antropología o la sociología tienen un gran calado en la construcción de la memoria pública y la recuperación del pasado reciente, no hay duda que la arqueología, como disciplina científica, también lo tiene y permite, además, subvertir la invisibilización de las víctimas en un grado que, debido también al eco mediático de las exhumaciones, no ha tenido paragón en estas últimas décadas.

En este sentido, la arqueología forense nos permite cartografiar la magnitud y la naturaleza de la represión y de las políticas de exterminio que se pusieron en marcha durante la guerra y durante la dictadura. Ahora bien, en los procesos de exhumación con metodología arqueológica, no sólo se recuperan cuerpos, pues junto a los restos óseos también se suelen documentar otros restos materiales. Es decir, repertorios de enseres que conforman la materialidad asociada a procesos de represión y violencia política de nuestro pasado reciente. Normalmente, se trata de objetos asociados a las víctimas que pueden ser enseres personales y/o evidencias de su muerte violenta.

Sin embargo, llama la atención el escaso interés teórico y conceptual que esta cultura material ha generado, hasta la fecha, en el ámbito de la reflexión arqueológica entre profesionales/académicos del Estado español. Jiménez y Herrasti ya abordaron este tema de forma preliminar en su contribución en el volumen monográfico Objects from the missing. Exhumations and uses of the material traces of mass violence, que analiza las prácticas de socialización de la memoria que se llevan a cabo a partir de la cultura material de las fosas en otros países (Baby y Nérard 2017). En el caso del Estado español, como apuntan estos autores: los objetos recuperados en las fosas comunes no están integrados en el patrimonio cultural, nada garantiza su integridad ni tampoco los atiende el ámbito jurídico debido a que estos delitos, cometidos hace 80 años, han prescrito según la justicia española. Hasta la fecha, de conformidad con los protocolos forenses que se aplican en los procesos científicos de exhumación (Orden PRE/2568/2011), los objetos 
recuperados junto con los cuerpos de las víctimas deben ser inhumados de nuevo. Y, por consiguiente, estos objetos se encuentran en un limbo jurídico y cultural que comporta que la arqueología del pasado reciente, especialmente en lo que se refiere a la exhumación de restos humanos, no sea considerada ni una cuestión patrimonial ni tampoco legal (Jiménez y Herrasti 2017).

En este artículo, tomamos como ejemplo la cultura material exhumada en las fosas del cementerio de Paterna (Valencia) para abordar varios objetivos. En primer lugar, mostrar una selección de los materiales conservados para, cualitativamente, poner en valor la cultura material exhumada más allá de los restos óseos y, además, destacar el grado de preservación de algunos elementos como la indumentaria, especialmente cuando se documentan cuerpos saponificados. En segundo lugar, intentar esbozar una tipología de los objetos documentados en las fosas que nos permita definir algunos tipos descriptores con los que trabajar y sistematizar la catalogación de los objetos. Por último, es nuestra intención abordar algunas cuestiones como el reto que supone la gestión, conservación y divulgación de esta materialidad. Pues, aún teniendo en cuenta que las exhumaciones se centran en la recuperación de los cuerpos y la identificación de las víctimas, consideramos que eso no nos exime a los profesionales del compromiso con la reflexión específica sobre los objetos exhumados en las fosas y sobre su posible vida/uso social en la investigación, la divulgación y la construcción de la memoria pública. En este sentido, planteamos que su uso social incide en la dimensión humana y en la memoria colectiva sin restar un ápice de importancia a su valor como elemento personal e identificativo de la víctima con la que apareció asociado.

\section{EL CEMENTERIO DE PATERNA: CARTOGRA- FÍA DEL TERROR}

Paterna es un municipio a escasos $8 \mathrm{~km}$ de la ciudad de València, que jugó un papel clave durante la guerra y durante la posguerra (Gabarda 2020a; Mezquida y Calpe 2021). En la actualidad cuenta con dos lugares de destacada significación para la memoria pública de nuestra historia reciente: la partida de El Terrer y el cementerio municipal; ambos intensamente vinculados (Gabarda 2020b).

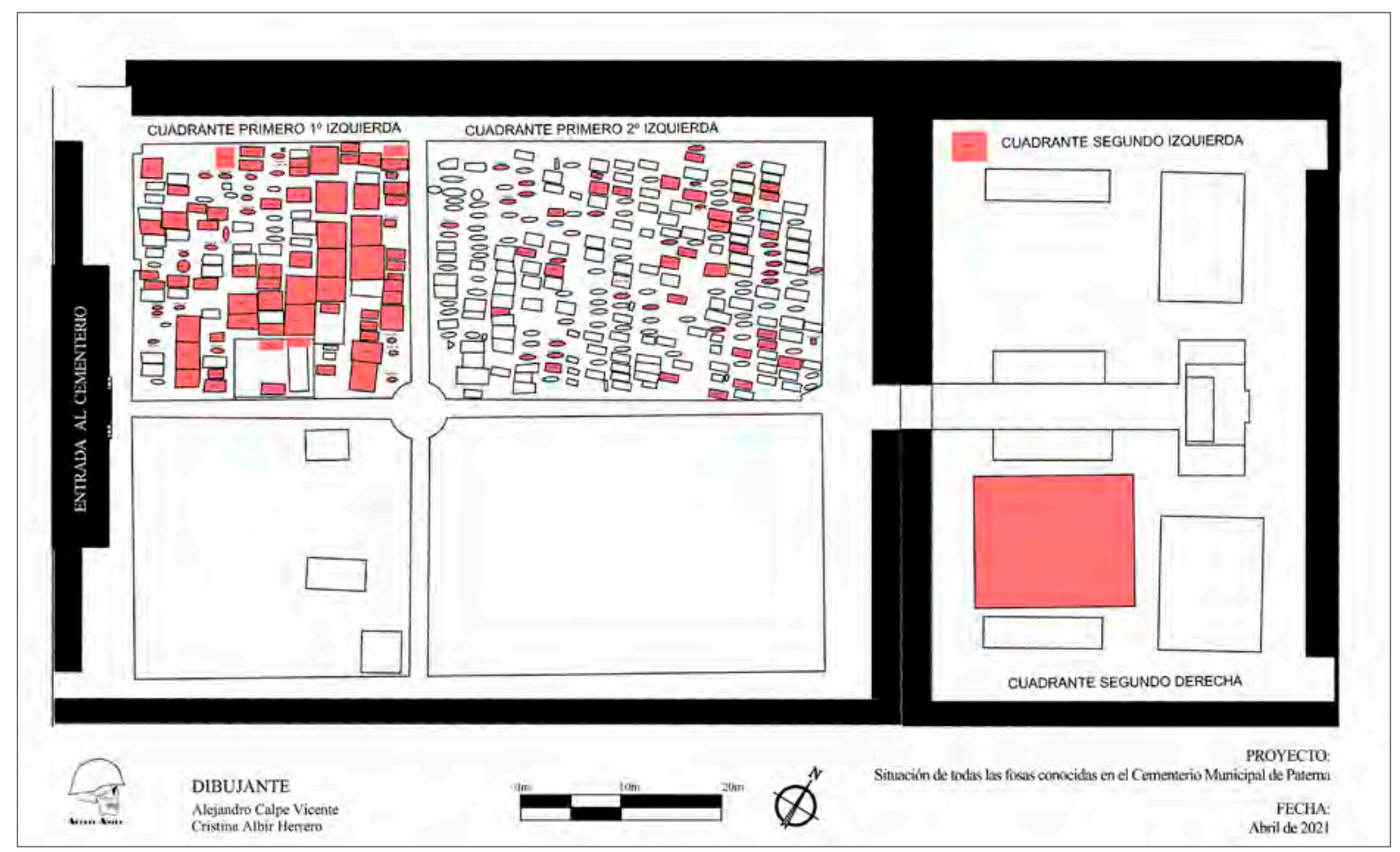

Fig. 1: Plano de ubicación de las fosas conocidas del cementerio de Paterna a fecha de abril de 2021. 
En El Terrer se encuentra el calificado popularmente como Paredón de España. Hoy en día apenas se mantienen visibles unos pocos metros de aquel muro, donde la dictadura franquista fusiló masivamente a personas acusadas de desafectas al nuevo régimen. Como apunta Gabarda, en Paterna comenzaron las ejecuciones el 3 de abril de 1939, tan solo cuatro días después de la entrada de las tropas a la ciudad, y finalizaron en noviembre de 1956; allí fueron fusiladas, al menos, 2237 personas, valencianos y valencianas, pero también de otros territorios de la geografía española (Gabarda 2020b: 172). Huelga decir que, a fecha de hoy, este lugar -verdadero punto negro de la represión y la violencia política del Estado franquista- no está señalizado ni cuenta con ningún elemento que explique lo que allí sucedió y que ponga nombre y apellidos a todas las personas que allí fueron asesinadas a golpe de fusil y tiros de gracia. Quizás sea también el momento de estudiar arqueológicamente, poner en valor y plantear la construcción de un centro de interpretación que permita musealizar el Terrer como espacio de memoria junto al cementerio de Paterna ${ }^{1}$.

Anexo a este lugar, a apenas unos centenares de metros, se encuentra el cementerio municipal de Paterna, donde coetáneamente a los fusilamientos, se excavaron las fosas comunes donde fueron lanzados y soterrados los cuerpos de esos hombres y mujeres víctimas de la violencia de la dictadura franquista. El recinto cementerial antiguo, que data de finales del s. XIX e inicios del XX, tiene planta rectangular y una extensión aproximada de $5500 \mathrm{~m}^{2}$. En él, se pueden distinguir dos espacios diferenciados: el denominado cuadrante primero con cuatro áreas de enterramiento y, en una zona inferior, el cuadrante segundo que se divide en dos subáreas de enterramiento. Ambos, a su vez, tienen definidas, según su distribución en referencia al pasillo central, un ala derecha y otra izquierda. El camposanto cuenta con, al menos, 154 fosas documentadas y su distribución en el espacio cementerial muestra lo que podríamos calificar como una cartografía del terror sin parangón en territorio valenciano y español ${ }^{2}$ (fig. 1). En una superficie de aproximadamente $1600 \mathrm{~m}^{2}$ (cuadrantes primero izquierda $1 \mathrm{y}$ 2 del cementerio) se cavaron más de un centenar de fosas que albergan los cuerpos amontonados de las más de 2200 personas, asesinadas en El Terrer en un intervalo de 17 años (fig. 2).

Las exhumaciones científicas se iniciaron en el cementerio municipal de Paterna en el año 2012, y hasta octubre de 2021 se han intervenido 27 fosas y siete nichos, que han permitido la recuperación de 1163 víctimas a través de procesos científicos llevados a cabo por tres equipos profesionales (PaleoLab, ArqueoAntro y Cavea) (Díaz-Ramoneda et al. e.p.; Moreno et al. 2021).

Las fosas de Paterna se encuentran en el interior del cementerio y albergan los cuerpos de personas provenientes, principalmente, de la cárcel Modelo y de la de Sant Miquel dels Reis, que fueron asesinadas en el paredón mediante ejecuciones sumarísimas colectivas ante pelotón de fusilamiento. En el camposanto, el espacio ha sido reutilizado y algunas de las fosas tienen afección con enterramientos ordinarios de momentos anteriores. Sin embargo, el recuerdo constante de los familiares ha permitido la señalización de las fosas y el

\begin{tabular}{|c|c|}
\hline Superficie & $\begin{array}{l}\text { El espacio cementerial antiguo cubre unos } 5500 \mathrm{~m}^{2} \text {. Dentro de esta área se ubican fosas, al menos, en una superfice } \\
\text { de } 1600 \mathrm{~m}^{2} \text { (especialmente en cuadrantes primero izquierda } 1 \text { y } 2 \text { ). }\end{array}$ \\
\hline$N^{\circ}$ fosas & 154 fosas; $\mathrm{n}^{\circ}$ de víctimas: 2337 personas. \\
\hline \multirow{2}{*}{$\begin{array}{l}\text { Datos tesina de } \\
\text { Gabarda (1985) }\end{array}$} & $\begin{array}{l}\text { Sobre el total de } 2237 \text { personas: } 2110 \text { víctimas son del PV }(93,38 \%, 2090 \text { hombres y } 20 \text { mujeres }) ; 109 \text { del resto de } \\
\text { España }(4,87 \%) \text { y } 19 \text { de procedencia desconocida e ilocalizable }(0,84 \%) \text {. } \\
\text { Sobre el total de víctimas sólo hay } 20 \text { mujeres }(0,89 \%) \text { : todas valencianas. }\end{array}$ \\
\hline & $\begin{array}{l}\text { Personas ejecutadas en Paterna por año: } 1939: 772 ; 1940: 948 ; 1941: 202 ; 1942: 170 ; 1943: 82 ; 1944: 32 ; 1945: 2 \text {; } \\
\text { 1947: } 6 ; 1948: 4 ; 1949: 2 ; 1950: 11 ; 1951: 3 ; 1952: 2 ; 1955: 1 ; 1956: 1 .\end{array}$ \\
\hline \multirow{2}{*}{$\begin{array}{l}N^{\circ} \text { sacas (Gabarda } \\
1993 \text { ) }\end{array}$} & 148 sacas en total. Sacas/días de fusilamiento por año: \\
\hline & $\begin{array}{l}29(1939) ; 22(1940) ; 16(1941) ; 33(1942) ; 16(1943) ; 10(1944) ; 2(1945) ; 2(1947) ; 4(1948) ; 1(1949) ; 6(1950) ; 3 \\
(1951) ; 2(1952) ; 1(1955) \text { y } 1(1956) .\end{array}$ \\
\hline $\begin{array}{l}\text { Uso intensivo de } \\
\text { las fosas }\end{array}$ & $\begin{array}{l}\text { Hasta la fecha se conoce, al menos, una decena de fosas que albergan más de una saca (F.13/14, F.20, F.21, F.91, } \\
\text { F.111, F.112, F.114, F.115, F.126, F.127, F.128); lo que permite confirmar la premeditación a la hora de establecer la } \\
\text { profundidad y uso intensivo del espacio. }\end{array}$ \\
\hline
\end{tabular}

Fig. 2: Datos de la cartografía del terror en el cementerio de Paterna (datos a fecha de abril 2021). 

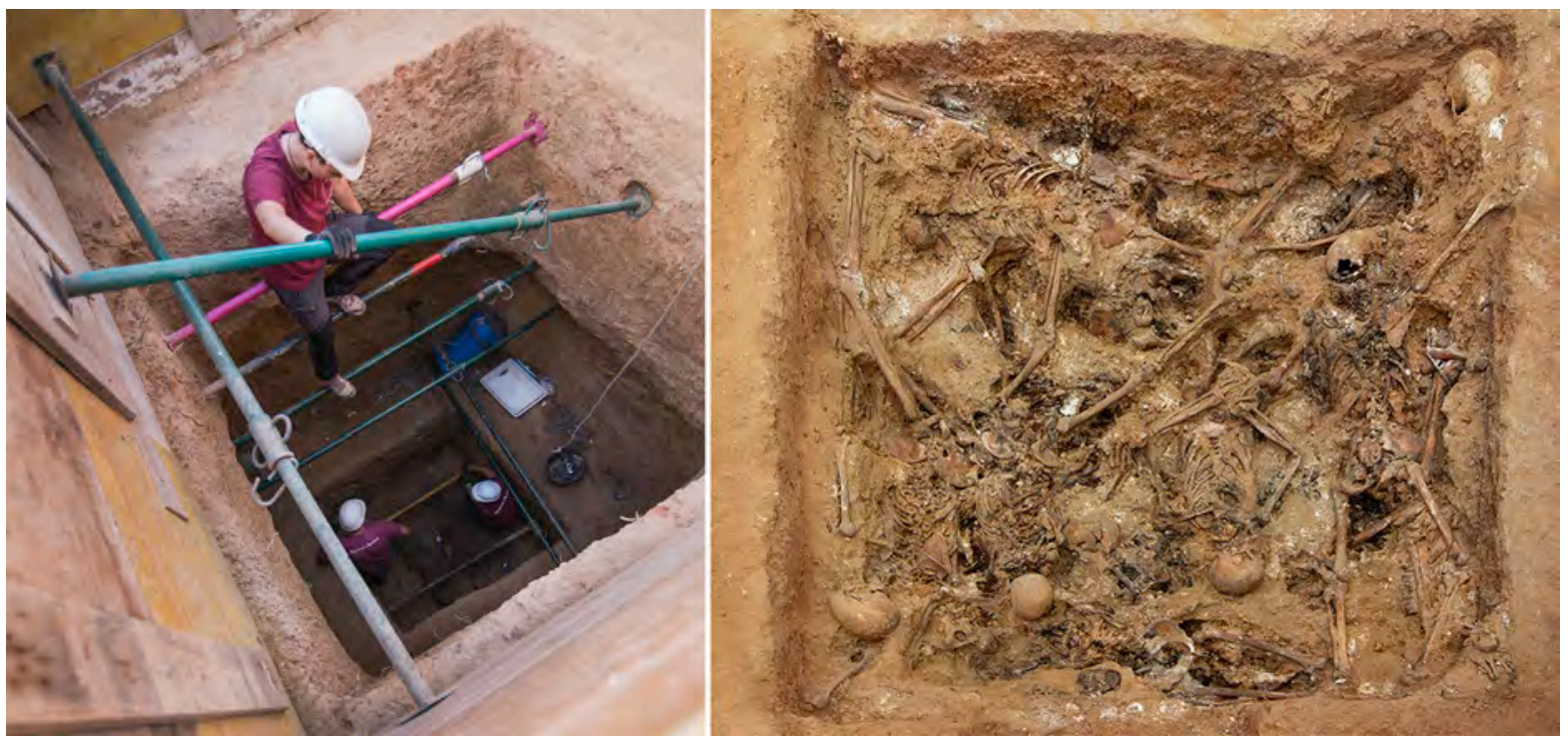

Fig. 3: Izquierda: Fosa 115, ejemplo de fosa-pozo del Cementerio Municipal de Paterna; durante los trabajos de excavación se alcanzó una cota de 5,5 m de profundidad y se exhumaron 144 víctimas. Derecha: Fosa 94; detalle de la disposición de cuerpos una vez extraída la capa de cal. Fotografías: Eloy Ariza-ArqueoAntro.

mantenimiento de mapas mentales que ubican las fosas en el espacio con un grado de certidumbre bastante preciso, al menos en el conocido como primer cuadrante izquierdo ${ }^{3}$ (fig. 1).

Desde un punto de visto arqueológico, la singularidad de las fosas del cementerio de Paterna, respecto al resto de fosas del territorio valenciano, responde a distintas variables. Por un lado, su morfología, pues se trata de estructuras en negativo de planta cuadrangular, que suelen albergar más de una saca de víctimas. Por otro, su tamaño ya que la reutilización del camposanto y el gran número de fosas que existe condicionan su distribución en el espacio de manera intensiva, dando lugar a fosas de dimensiones reducidas (normalmente inferiores a los $2 \times 2,50 \mathrm{~m}$ ) que se han excavado en el terreno natural anexas unas a otras. Esto implica que, en algunos casos, cuando las distintas sacas se superponen, la fosa alcance una profundidad considerable (hasta la fecha se ha llegado a los $6 \mathrm{~m}$ en la fosa 128). En este escenario, nos encontramos ante estructuras en negativo que no responden a la tipología común de fosa-zanja de orientación longitudinal y una profundidad relativamente escasa, como las que se documentan en el Cementerio de Castelló, en las fosas del Frente de Levante o en las cunetas del resto del Estado español, sino que en Paterna se documentan fosas cuadrangulares que pueden ir desde escasamente un metro de profundidad a ser bastante hondas, convirtiéndose en fosas-pozo de varios metros (Gabarda et al. 2019, Mezquida et al. 2021; Díaz-Ramoneda et al. e.p.). Ello implica que, cuando se superan los 4 o 4,5 m de profundidad, entran en juego otros condicionantes como la naturaleza del subsuelo, el nivel freático o la temperatura que, entre otras variables y junto a la capa de cal que sella la saca, generan atmósferas donde los procesos de descomposición y putrefacción de los cuerpos se ralentizan y tienen lugar procesos como la saponificación cadavérica. La saponificación es un proceso inducido por un alto nivel de humedad que favorece la conservación del cuerpo a partir de un proceso de cambio químico que afecta a la grasa corporal, que se transforma a través de la hidrólisis en un compuesto semejante a la cera o el jabón (Casas et al. 2006; Etxeberria y Serrulla 2019), lo que permite que tanto los cuerpos como las evidencias materiales que se localizan, aparezcan en un estado de preservación excepcional. Así se ha documentado hasta la fecha en las F.128 y F.111 (parcialmente en las F.112, 115 y 127), donde un grado de conservación tanto de los restos antropológicos como de los objetos, ha permitido la recuperación de indumentaria y un número excepcional de evidencias materiales asociadas a los cuerpos exhumados, que convierten al cementerio de Paterna en un escenario singular y bastante único en lo que respecta a los procesos de exhumación, que se convierten en un reto personal, profesional y metodológico (fig. 3). 
En Paterna, los cuerpos de las víctimas se documentan generalmente amontonados unos sobre otros, sin receptáculo funerario, indicando un trato poco ortodoxo, que no se hubiera dado en sepulturas ordinarias de personas consideradas de bien ${ }^{4}$. Esa disposición de cuerpos abigarrados confirma la magnitud de los fusilamientos y la existencia de sacas, es decir, permite definir grupos de víctimas coetáneas, fusiladas e introducidas en la fosa simultáneamente. No obstante, durante el proceso de excavación se han podido documentar, al menos, cuatro tratamientos de los cuerpos: víctimas que se inhuman de manera individualizada previo pago por parte de la familia; víctimas individualizadas en cajas funerarias sufragadas por las propias familias, que se entierran en la fosa común (ambos casos denotan una intención de recuperación futura del cuerpo); víctimas ordenadas con cierta precisión en las fosas de menor profundidad o en las sacas superiores de fosas más hondas, lo que implica una deposición de los cuerpos más precisa y cuidadosa por parte del enterrador ${ }^{5}$; y la práctica generalizada de víctimas lanzadas de manera descuidada, que genera amontonamiento de los cuerpos (Díaz-Ramoneda et al. e.p.).

\section{ARQUEOLOGÍA, FOSAS Y MATERIALIDAD}

La materialidad es una dimensión básica de la arqueología; lo ha sido desde sus orígenes como disciplina científica. La cultura material arqueológica presenta, además, una amplia trayectoria de estudio especialmente para los períodos de la prehistoria, protohistoria y mundo clásico, gracias tanto al trabajo del mundo académico como de la arqueología de gestión. Sin embargo, los referentes donde poder sistematizar y analizar la materialidad del pasado reciente en perspectiva arqueológica tienen cada vez más presencia y son ciertamente enriquecedores (Haglund et al. 2001; Schofield 2005; Olsen 2010; Theune 2010; Olsen et al. 2012; González-Ruibal y Ayán 2018; Renshaw 2018; Schute 2018). Los trabajos arqueológicos sobre la guerra civil y el primer franquismo crecen exponencialmente, en especial vinculados al patrimonio bélico, el estudio de campos de concentración, la recuperación de los cuerpos de soldados del frente y las víctimas de la violencia (por citar algunos trabajos recientes: Polo et al. 2012; Muñoz-Encinar et al. 2013; Fortuna et al. 2017; Mezquida 2017; Moreno y Sapena 2017; Ramos 2019; Mejías 2020; Solé y Gallego 2020). De manera que no hay duda que estas praxis consolidan a la arqueología como una disciplina pública, política y social donde el estudio del pasado reciente y el conflicto no pueden obviarse. La arqueología, por tanto, deviene clave en la recuperación de la memoria, en la anamnesis de la justicia (Zamora y Mate 2011) y en la ecuación de la denominada justicia transicional, pues permite poner el foco en el punto de vista de las víctimas (Hazan 2008) y abordar no únicamente la guerra y la violencia, sino cómo ésta y sus consecuencias afectan a la sociedad.

No obstante, y volviendo al tema central que aquí nos ocupa (la cultura material exhumada de las fosas del franquismo), también es cierto que aún queda pendiente en la arqueología del Estado español la reflexión/debate teórico y metodológico centrado en una parte de esa materialidad contemporánea que no es monumental, ni osteoarqueológica ni arquitectónica. Nos referimos a los objetos exhumados en las fosas, cuyo reconocimiento y análisis, aunque ha experimentado un despegue evidente, sigue siendo un tema pendiente. A todas luces, es una cuestión que produce cierto vértigo. Quizás la proximidad cronológica, la naturaleza de esos objetos y los contextos en que se documentan pueden generar rechazo al trasladarnos a episodios de muerte violenta de un pasado aún sin cerrar. También es cierto que nos traslada a una escala microespacial donde priman objetos de uso cotidiano contemporáneos que para algunos quizás tampoco tienen valor patrimonial per se y, de hecho, la legislación vigente ofrece lagunas sobre su naturaleza, grado de protección y gestión. Y, por otro lado, también es una materialidad que exige de un compromiso y una pulcritud ética, científica y humana, que no podemos obviar. Huelga decir que la responsabilidad ética en la práctica arqueológica debe ser algo irrenunciable en nuestro trabajo (Fernández 2006; Scarre y Scarre 2010; González-Ruibal y Moshenska 2015; Olsen y Witmore 2015).

No obstante, sí existen referentes teórico-metodológicos en otros países que abordan las exhumaciones de fosas comunes y que ponen el acento tanto en los restos óseos de las víctimas como en los objetos que aparecen asociados a ellos durante la excavación. En estos procedimientos la metodología arqueológica siempre va de la mano con las técnicas forenses y genéticas, pero también bajo el paraguas de los paradigmas de la sociología y la antropología social y cultural. Por citar algunos ejemplos, baste consultar el caso de las fosas comunes en $\mathrm{Ar}$ gentina (Crossland 2000); Chipre (Sant-Cassia 2005); Timor (Blau y Skinner 2005); Iraq (Stover et al. 2003) o en Bosnia-Herzegovina (Wagner 2008) o el volumen 
monográfico sobre la cultura material exhumada de fosas comunes en distintos proyectos internacionales (Baby y Nérard 2017).

En nuestro caso, proponemos el análisis arqueológico de la materialidad exhumada de las fosas en diálogo constante con los enfoques que la historia, la antropología y la etnografía nos ofrecen; dado que las tipologías de objetos, los materiales y los contextos en que se documentan, nos permiten acudir a fuentes orales, archivos y documentación ante-mortem en un grado cualitativo y cuantitativo muy singular si lo comparamos con otros contextos crono-culturales arqueológicos. En este sentido, algunos autores han acuñado los conceptos de etnografía de las exhumaciones o la etnografía de la fosa, como procedimientos científicos en los procesos de localización e identificación de víctimas, donde como complemento a la metodología arqueológica y forense (de campo y de laboratorio), el trabajo desde la antropología socio-cultural, la sociología y los proyectos de documentalistas son cruciales (Hallam y Hockey 2001; Ferrándiz 2006; 2014 y 2020; Renshaw 2011; Robben 2017; Iturriaga 2019; García y Gadea 2020). Porque como apunta Solé: la fosa en sí misma, la materialidad ósea y todos los objetos que la acompañan, es una fuente que también se enriquece del hecho de ser investigada desde la interdisciplinariedad (2019: 451).

Precisamente, en esta cadena operativa a menudo hay fases de trabajo que no son lineales ni consecutivas, pues el trabajo a pie de fosa puede dar origen a la localización de nuevas evidencias bien sean materiales (objetos exhumados) o bien testimonios orales. De lo que no hay duda es de que, además del registro arqueológico (cuerpos y objetos), contamos con actores sociales (familiares vivos), testimonios orales o documentos escritos que permiten que la triada Arqueología, Historia y Antropología aborden conjuntamente el estudio, análisis y divulgación de nuestro pasado reciente.

Cuando estudiamos enterramientos en fosa en otros contextos de diferente naturaleza y cronología, la arqueología analiza cómo se ha realizado la fosa; cómo se ha practicado la inhumación, se define e interpreta si su tipología y sus dimensiones responden a algún rito; se estudia el ajuar funerario asociado al cuerpo (en los casos en que se documente). En este sentido, las excavaciones con metodología arqueológica que se implementan en los procesos de exhumación son actuaciones científicas donde además de la recuperación del cuerpo de las víctimas ${ }^{6}$, también se estudia y documenta arqueológicamente y de manera individualizada su disposición, sus características anatómicas y su relación con otros cuerpos y evidencias que puedan incidir en la identificación de individuos y la causa de la muerte. Porque si bien es cierto que la exhumación de una saca nos permite hablar de "comunidad de muerte", es decir, de personas que compartieron la muerte al haber sido asesinadas y sepultadas juntas (Ferrándiz 2011: 541), también es cierto que la materialidad asociada a los cuerpos puede complementar las tareas de identificación y ofrecer información sobre individuos concretos, que sumada a los estudios de información y testimonios se use junto a las pruebas de ADN (Renshaw 2010).

Ferrándiz define las fosas de la derrota como memoriales del miedo (2011: 527) al contribuir con su presencia a consolidar las raíces del régimen dictatorial, en lo que Rodrigo describe como una pedagogía de la sangre que paraliza las resistencias (2008: 73). Las autoridades franquistas gestionaron las fosas del cementerio de Paterna de un modo deleznable. En el caso de estudio que aquí nos ocupa, tratamos con fosas comunes masivas, excavadas con premeditación dentro del camposanto, cuya finalidad no es dar sepultura ritual a los muertos (al menos de manera ortodoxa) sino esconder sus cuerpos, pero visibilizar su muerte. Por sus dimensiones y características responden a un rito funerario (si así se pudiera denominar) que nace de la muerte violenta y de la deshumanización de la víctima que es concebida como traidor y culpable. De manera que la simbología que tiene adquiere todo su significado enmarcada en el contexto que produce las muertes y las fosas, es decir, la victoria y el exterminio del adversario que es conceptualizado como la Anti-España.

Era $-\mathrm{y}$ es evidente- el rol que estos enterramientos masivos tuvieron: establecer un tratamiento diferenciado de las víctimas y mostrar de manera ejemplarizante esos asesinatos y el tratamiento que se hacía de esos cuerpos. Era además una manera de infundir miedo y aleccionar. Los mataban a la luz, porque fusilaban y mataban sin temor, sabedores de su impunidad. Sin embargo, una vez muertos los ocultaban bajo tierra sin dejar que tuvieran acceso a un ritual y sepultura dignos. Parece que los victimarios seguían esa máxima de que no existe lo que no se ve: estos muertos no estaban Presentes ni podían ser velados ni llorados, pues las manifestaciones públicas de su muerte estaban prohibidas. Siguiendo a Ferrándiz podemos confirmar que las fosas comunes fueron un paisaje físico, político, simbólico y social que intencionalmente contribuyó a tejer un discurso hegemónico que invisibilizó 
y silenció a los vencidos, sus historias y sus memorias, en pro de relatos de muerte ritualizados que heroizaban a los vencedores y los caídos que éstos consideraban como propios (Ferrándiz 2009).

Privar a una persona de una sepultura digna es en nuestra sociedad un verdadero castigo para la víctima y para la familia, pues la una es despojada de humanidad y la otra es estigmatizada de por vida por la sociedad y sufre la imposibilidad de cerrar su duelo, perdiendo el derecho a vivir la muerte del familiar acorde a los ritos sociales establecidos (García y Gadea 2020; Santonja 2021). Y es que el matiz del proceso y del concepto no es baladí: no murieron, los asesinaron; no los enterraron, los metieron bajo tierra, sepultados por capas de tierra, cal y los cuerpos apilados de otras muchas víctimas que conforman paquetes estratigráficos que pueden alcanzar varios metros de profundidad.

La calificada por Marianne Hirsch como generación de la posmemoria, es decir, aquellas segundas o terceras generaciones de las víctimas directas que han heredado historias traumáticas y duelos no cerrados (2015), se han aferrado a la materialidad (pipa, corbata, fotos...) para conservar y transmitir esos recuerdos. Los objetos encapsulan unas memorias y unas historias que intentaron ser borradas y aniquiladas desterrándolas bajo tierra, pero cuyo recuerdo ha pervivido en sus casas, a través de las familias. Ahora, esas memorias se hacen públicas y vuelven a la vida con la exhumación. Resulta significativo que los familiares hablen de reconstruir la memoria y la historia de sus muertos desde la vida, desde el presente, a partir de lo que cuenta la fosa, lo que cuentan los cuerpos y los objetos. Las familias hablan de buscar (estoy buscando a mi abuelo) y de recuperar (queremos recuperarlo) para poder dar sepultura digna, para cerrar una etapa de décadas de "mal entierro" y para contar y recuperar sus historias (no queremos que se les olvide). Esta dualidad Fosa-Muerte, Memoria-Vida convierte al proceso de exhumación en una práctica reparadora para las familias.

\section{OBJETOS EXHUMADOS: LA MATERIALIDAD DE LAS FOSAS DE LOS VENCIDOS}

La cultura material que acompañaba a estos muertos (cuando se conserva) supone para la documentación arqueológica y antropológica una foto instantánea de esas personas y nos permite analizar la naturaleza de su muerte y algunos destellos de lo que fue su vida ${ }^{7}$.
En el proceso científico de exhumación, esos objetos son nuestros fósiles directores, pues permiten, por ejemplo, confirmar la datación de los muertos. Es cierto que tanto la documentación de archivo como los testimonios nos permiten conocer el día, el año, la saca... pero ante la aparición de restos humanos en la exhumación se debe confirmar tanto la muerte violenta como el hecho de que, efectivamente, estamos ante asesinatos perpetrados durante la dictadura. Y ahí la materialidad arqueológica es clave pues confirma que estamos ante cuerpos con claras evidencias de muerte violenta, que se asocian a objetos que se pueden datar -en el caso de las fosas de Paterna- entre los años 1940 y 1950 y no de otras épocas. De manera que ante la pregunta de ¿cómo sabéis que no son más antiguos? La osteoarqueología, la materialidad y/o la identificación de anomalías estratigráficas son cruciales.

En lo que respecta a los objetos exhumados, al menos en lo referente a la materialidad documentada en las fosas del cementerio de Paterna, la experiencia de sucesivas excavaciones (concretamente 27 entre 2012 y 2021) ha permitido documentar unos repertorios de objetos que pueden ser clasificados en diferentes categorías (Iglesias et al. 2018: 154-155; Díaz-Ramoneda et al. e.p.). No obstante, lejos que intentar definir una tipología exhaustiva de esta cultura material, al menos sí hemos intentado definir algunos tipos descriptores que nos permitan indexar los objetos. Nuestro interés no se limita únicamente a describir los objetos en sí mismos sino analizarlos y estudiarlos como evidencia y testimonio del pasado contemporáneo en una praxis que como indicábamos vincula a la arqueología con las prácticas etnográficas asociadas al pasado reciente. Proponemos que, además del pertinente inventario de los materiales siguiendo los estándares tradicionales (descripción, medidas, peso, materia, técnica, etc.), se detalle una clasificación de objetos centrada en descriptores que nos permitan, no sólo la mera descripción de las piezas, sino la catalogación de ese material para poder extrapolar información sobre los individuos y hacer lecturas a partir de los objetos para abordar, en perspectiva social y antropológica, temas como el cuerpo y vida material, la sociedad, la política, la economía, la cultura y la educación o las creencias. En este sentido, quizás habría que valorar la necesidad de un trabajo clasificatorio que se estructure formalmente más que como una tipología, como un tesauro, es decir, un vocabulario formado por términos que guardan entre sí relaciones semánticas y genéricas: de equivalencia, jerárquicas y 
asociativas. De esta manera el inventario, estudio y catalogación de estos objetos permitiría un control tipológico a la vez que terminológico muy útil para el análisis, descripción y recuperación automatizada de esa información.

Así, por ejemplo, encontramos objetos que nos permiten abordar desde la disciplina arqueológica, la histórica y desde la antropología social y cultural temas diversos como: la muerte, la vida carcelaria, las creencias, algunos ritos del ciclo vital (noviazgo, matrimonio, nacimiento...), el ocio, la higiene y la salud o el cuerpo, entre otros. Los objetos además tienen un valor y una potencialidad a la hora de humanizar y encarnar vidas, memorias e historias que probablemente no tengan otros soportes, fuentes o documentos históricos. Son variados los calificativos que desde distintos planteamientos teóricos y conceptuales se barajan cuando tratamos con esta materialidad del pasado reciente, especialmente la vinculada a crímenes masivos y vulneración de derechos humanos. Por un lado, algunos autores han destacado el carácter aurático de los objetos (González-Ruibal 2008: 18), centrándose en la capacidad que tienen de despertar emociones y afectos. Cabe matizar, no obstante, que el aura de los objetos, siguiendo a Walter Benjamin (2003), incide específicamente en la capacidad de generar extrañamiento y, por tanto, pueden producir tanto afectos como desafectos.

Por otro lado, también se ha acuñado el término testimonial objects (Hirsch y Spitzer 2006: 358). Estos autores parten de la noción de punctum de Roland Barthes y conciben los objetos como puntos de intersección entre el pasado y el presente. Es una propuesta que incide tanto en la espacialidad como en la temporalidad a la hora de trabajar la memoria y concibe los objetos como nodos de memoria.

Recientemente, Iturriaga ha propuesto el concepto activated objects destacando así que los objetos junto con los cuerpos no son sólo evidencias materiales, sino que a través de las narrativas que los discursos científicos ofrecen con los procesos de exhumación, los objetos también participan activamente en la construcción de la memoria y el conocimiento del pasado (Iturriaga 2019). Es un planteamiento que, parafraseando a Latour (1987), propone que los objetos pueden tener voz propia.

En una formulación complementaria, Muñoz-Encinar destaca que estos artefactos se vinculan con la identidad individual de las víctimas marcando su manera de vestir, sus hábitos personales, su ideología, su ocupación, género, etc. (2019: 762).
Partiendo de este escenario de planteamientos, lo que es evidente es, por un lado, la potencialidad de esta cultura material para cimentar relecturas sobre las víctimas, pues los objetos son elementos descriptivos y definitorios de sus portadores. Y, por otro lado, la capacidad que tienen estos objetos para producir reacciones en la gente: dolor, miedo, emotividad. En este sentido, la mera contemplación de estos objetos produce en los familiares una conexión directa con los recuerdos y las historias de vida de sus víctimas, pues encuentran una vinculación con su historia familiar y esos objetos encarnan a la persona ausente. En muchos casos, el impacto se magnifica ya que algunas personas nunca conocieron a ese familiar asesinado y es, ahora, cuando conocen su historia a través de sus huesos, sus objetos y la comunidad de muerte que con él se ha creado en la fosa. Podríamos hablar de que la aproximación de las familias a esa materialidad bien podría vincularse a los enfoques fenomenológicos, es decir, aquellos basados en las relaciones entre sujeto y objeto, pues no cabe duda de que se cimientan en sus experiencias sensoriales y emocionales.

Sin embargo, cuando el observador no tiene un lazo de parentesco con la víctima, estos objetos humanizan los huesos exhumados. El impacto es aún mayor cuando la persona percibe al observar la fosa que esos huesos no son de cuerpos de otras épocas remotas, sino que se advierte la conexión con el presente, con nosotros, al reconocer zapatos, hebillas, anillos, una pipa o un lápiz como los que nosotros mismos o nuestros padres aún conservamos o los que identificamos en las fotos familiares de nuestros abuelos y bisabuelos. Es una cultura material que reconocemos, entendemos y patrimonializamos. No hay que recurrir a manuales ni libros para saber qué es y para qué sirve. Y en esa ecuación, la empatía hace que automáticamente se piense, que esos huesos y esos objetos nos hablan de gente que tuvo vidas y familias semejantes a las nuestras y tan cercanas que podríamos ser nosotros mismos. Porque estos objetos forman repertorios personales/familiares, pero la arqueología a través de su exhumación, su estudio y divulgación permite que se conviertan también en repertorios culturales e históricos colectivos que vinculan el pasado reciente y el presente.

Estos cuerpos y objetos nos hablan de un pasado traumático, de muertes violentas y de represión, pero el estudio de esta materialidad, junto con los cuerpos, los testimonios, la documentación histórica, también nos permite analizar e individualizar con profunda significación personal, los relatos sociales vinculados a esas historias y 
a sus vidas. Una pluralidad de nombres, siglas, procedencias, credos, militancias que la dictadura uniformizó y deshumanizó como una gran masa de culpables, desafectos, fanáticos, subversivos y antipatriotas; una especie de degeneración de la raza española que la España de Franco tenía que purgar, hacer desaparecer y enviar al paredón y al olvido. No obstante, esta política premeditada de deshumanizar y uniformizar a la oposición y a la República con un reduccionismo y un maniqueismo feroz, se desmonta con argumentos científicos, con la Historia, la Antropología y la Arqueología. Así, los estudios históricos de Gabarda definen listados de víctimas con perfiles diversos tanto en edades como en profesiones (obreros, labradores, comerciantes, maestros, funcionarios, artistas, etc.) y en siglas políticas (anarquistas, comunistas, socialistas) (2020a: 102). Y la arqueologia y la antropología corroboran que las personas exhumadas de las fosas y los objetos asociados a ellas, que se recuperan en los procesos científicos de identificación, localización y exhumación, nos dejan ver una población plural y no aquella especie de horda de demonios rojos con tridente y cola (Moreno e.p.).

De manera que, si aceptamos, como recoge Ferrándiz, que excavar las fosas significa, literalmente, excavar la memoria (2007: 5), no podemos más que leer y tener presente el registro arqueológico al completo. Y, por tanto, la materialidad en su conjunto debe ponerse en valor para recuperar y socializar la memoria de nuestro pasado reciente y para visibilizar alteridades y memorias que durante demasiado tiempo se habían mantenido soterradas en una invisibilidad que resulta reveladora de lo que ha sido nuestra historia reciente.

\section{CLASIFICACIÓN DE OBJETOS}

Como se ha indicado al inicio del texto, uno de los objetivos del artículo es ofrecer una selección de los materiales documentados en los procesos de exhumación del cementerio de Paterna. En este sentido, no se pretende en este trabajo un inventario ni un estudio cuantitativo de los materiales sino mostrar la variedad de objetos conservados para, cualitativamente, poner en valor la materialidad exhumada más allá de los restos óseos e intentar definir algunos tipos descriptores con los que trabajar y sistematizar la catalogación de los objetos. Huelga decir que la clasificación de objetos se ha definido a partir del análisis del registro arqueológico de Paterna, donde se han podido exhumar hasta octubre de 2021, 27 fosas y 1163 cuerpos del total de 2237 personas que allí fueron asesinadas (Moreno et al. 2021).

\section{EVIDENCIAS DE VIOLENCIA Y REPRESIÓN (fig. 4)}

\section{Munición}

En el registro arqueológico se recuperan tanto proyectiles de fusil como proyectiles de pistola. Lo que nos permite

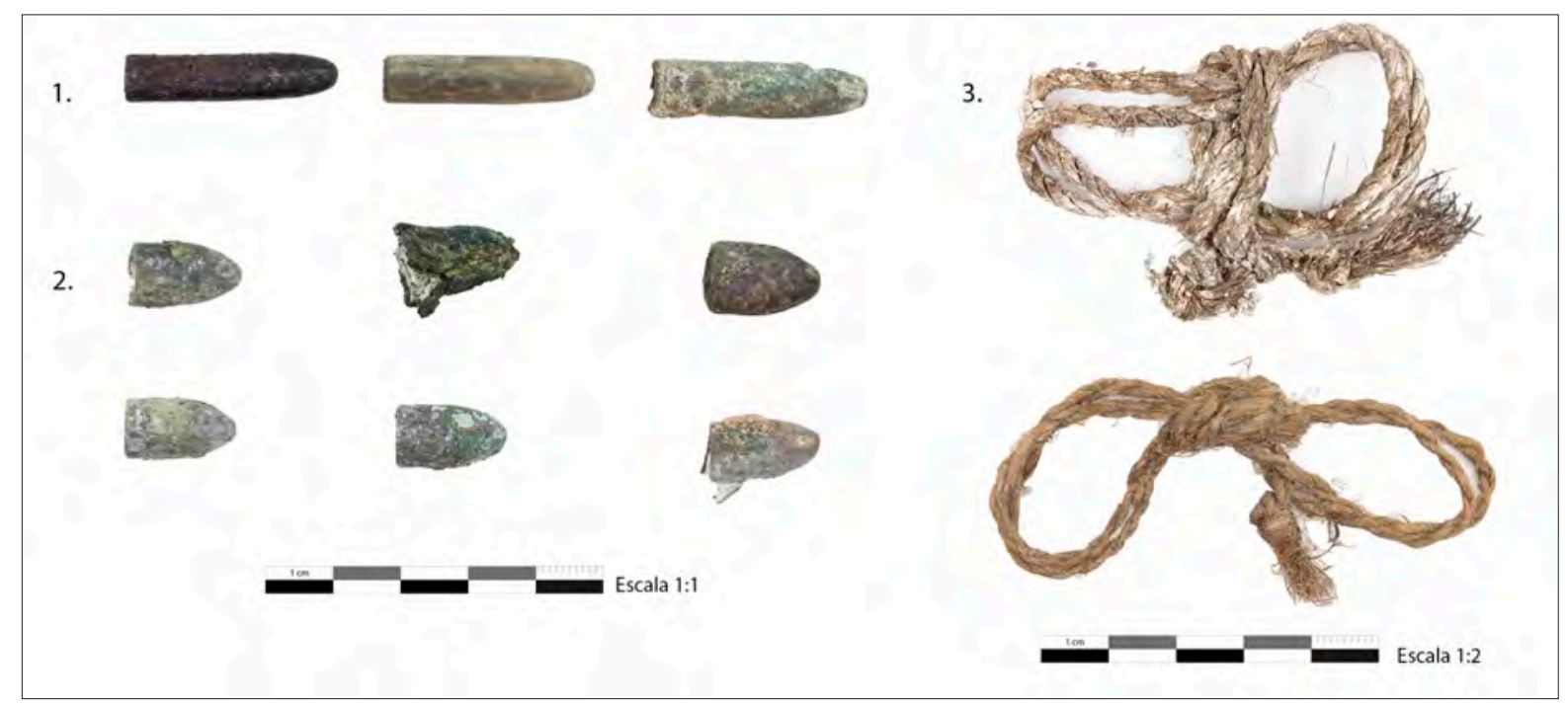

Fig. 4: Selección de materiales documentados en el interior de las fosas: 1: proyectiles de $7 \mathrm{~mm}$ de fusiles Máuser empleados para los fusilamientos; 2: proyectiles de $9 \mathrm{~mm}$ correspondientes con el tiro de gracia. 3: ligaduras de esparto para maniatar a las víctimas (arriba: Fosa 128 , abajo: Fosa 111). Fotografías: Eloy Ariza-ArqueoAntro. 
interpretar un uso diferenciado de distintas armas para el fusilamiento y para el posterior tiro de gracia, así como plantear qué cuerpos de seguridad del Estado formaban parte de los pelotones de fusilamiento, o incluso documentar la participación de civiles o paramilitares (al localizarse proyectiles de caza o de avancarga). En este sentido, el análisis de la munición documentada ha identificado proyectiles de $7 \mathrm{~mm}$ de fusil Máuser, un arma reglamentaria del ejército español; y proyectiles de $9 \mathrm{~mm}$ corto y largo utilizados en arma corta tanto por la Guardia Civil como por el ejército (Mezquida et al. 2018: 143-144; Gabarda et al. 2019: 58). Sin embargo, los proyectiles de $9 \mathrm{~mm}$ largo también eran empleados por subfusiles RU-35, Si-35, TN-35 y Atlántic, cuyo uso en la posguerra se asocia a la Guardia Civil. Recientemente, también se han registrado proyectiles de pistola de un calibre inferior (7,65 mm), en la Fosa 114, lo que además podría significar el cambio y los diversos gustos a la hora de escoger su armamento entre los jefes de los pelotones de ejecución, encargados de rematar a las víctimas.

\section{Ataduras en las manos}

Normalmente es cuerda de esparto trenzada o hilo de alambre que a modo de esposas, funciona para aprisionar las muñecas para reducir la movilidad de las víctimas.

\section{Vendajes}

Algunos cuerpos se documentan con restos de telas de algodón colocadas en el cuerpo para sujeción o cura de heridas en forma de gasa o cabestrillo, lo que indicaría que previamente al fusilamiento, muy probablemente durante su estancia en prisión o en el traslado al paredón sufrieron algún tipo de violencia que les provocó heridas y traumatismos.
La exhumación de estos objetos confirma que estos cuerpos son de víctimas de violencia y privación de libertad. Estas evidencias materiales interpretadas conjuntamente con las heridas y orificios en los cuerpos, la ropa con sangre y las fracturas perimortem nos ofrecen argumentos para hablar de prácticas de tortura/violencia física, crímenes y de violaciones de derechos humanos.

\section{INDUMENTARIA Y COMPLEMENTOS}

Por lo general en las fosas, junto a los cuerpos de las víctimas, se recuperan fragmentos de cierres, hebillas, piezas de vestir, botones y también restos de zapatos y tejidos. No obstante, en aquellas donde se produce la saponificación cadavérica se documenta la vestimenta completa de los individuos en un grado de conservación excepcional (fig. 5).

La singularidad del registro arqueológico en las sacas saponificadas del cementerio de Paterna posibilita la catalogación de indumentaria con un grado de detalle excepcional, que describe a cada individuo de manera personalizada desde la ropa interior a la vestimenta y el calzado. Este inventario, catalogación y estudio de la ropa nos permite interpretar variables vinculadas al mundo de trabajo y los oficios, la estructura social y las clases o también el género de las víctimas.

\section{Vestimenta}

- Calzado. Respecto al calzado se documentan cuatro tipos: botas (calzado que cubre todo el pie, el tobillo y una parte variable de la pierna), botín (bota de piel fina, generalmente puntiaguda y de vestir, que llega hasta encima del tobillo; puede llevar cordones o abrocharse con

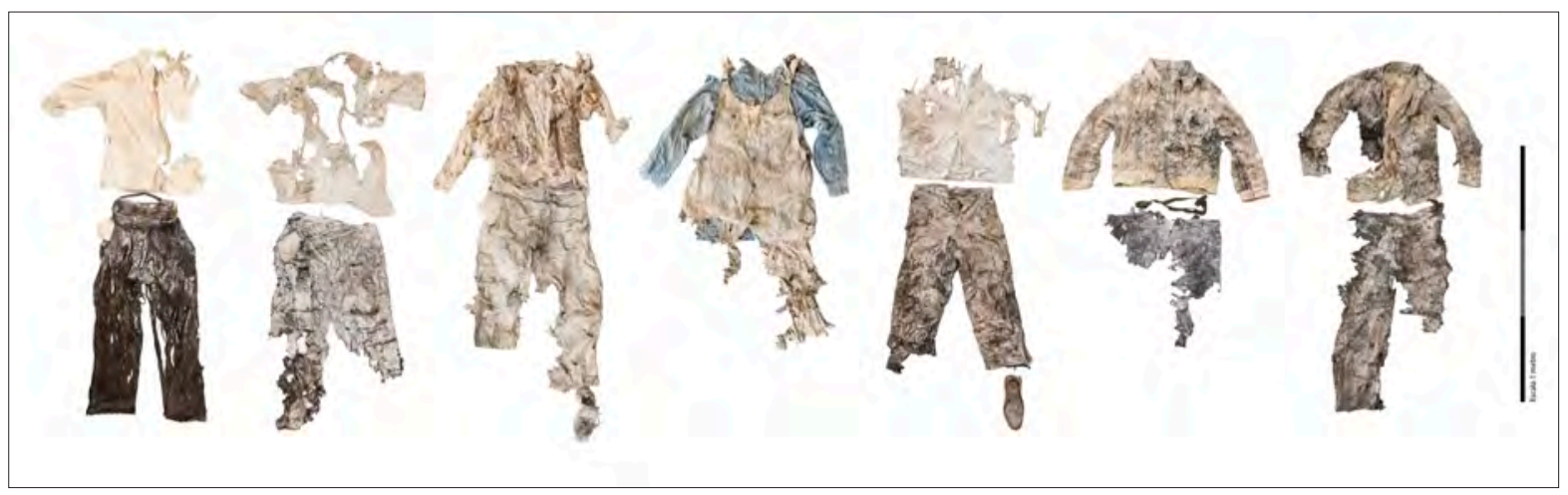

Fig. 5: Selección de parte de la indumentaria recuperada junto con los cuerpos exhumados en la Fosa 128. Fotografías: Eloy ArizaArqueAntro. 
cierre, hebilla o botones), alpargatas (calzado de lona, con suela de esparto, cáñamo o goma, que se sujeta al pie por presión o con unas cintas que se atan al tobillo), sandalias (calzado ligero sujeto al pie con correas, cintas o cordones), zapato de salón masculino (zapato cerrado generalmente de cuero, de línea simple, sin cierres ni adornos, plano o con tacón y con y sin cordones), zapato de salón femenino (zapato cerrado generalmente de cuero, de línea simple, suele ser escotado, de punta más o menos redondeada y puede tener diferentes alturas de tacón).

- Ropa interior: Calcetines (de algodón), calcetines masculinos con liga para sujetar a la pantorrilla, calzones masculinos con perneras de distintos largos: calzoncillos cortos hasta la rodilla, calzoncillos largos hasta los tobillos, camiseta interior (de tirantes, de manga larga y de manga corta).

- Pantalones: mayormente son pantalones largos con perniles que terminan en forma recta. Los hay de diferentes tejidos: algodón, pana, de tela vaquera o denim. Es frecuente que tengan bolsillos y botones, y la cintura suele incluir algún tipo de cinturón.

- Parte superior: Camisetas de manga larga y de manga corta, camisas (prenda de tela con cuello y mangas que cubre el torso y abotonada por delante), chalecos (prenda sin mangas que se viste sobre la camisa), jerséis o suéters (prenda de punto, generalmente de lana o algodón, cerrada y con mangas), chaquetas (cubre hasta la cadera) con distinto tipo de cierre (cremallera, botones), abrigo (prenda de vestir larga, con mangas, abierta por delante y con botonera, mono-peto de una pieza con pantalón largo (parte de arriba con mangas o con tirantes)

- Complementos: Corbatas, pañuelos, cinturones, tirantes, gemelos, alfiler de corbata, bufanda, faja (pieza de tela en forma de cinta ancha que se coloca alrededor de la cintura).

\section{Objetos personales (fig. 6)}

Los cuerpos exhumados en las fosas suelen conservar enseres personales asociados. Este tipo de materiales pueden servir como elementos identificativos de la persona y también nos permiten, desde una lectura socio-cultural, conocer costumbres, hábitos y prácticas de las víctimas y también inferir sus actividades o profesiones.

- Abalorios y complementos destinados al adorno personal como reloj de pulsera, colgantes, pendientes, brazaletes, anillos.

- Objetos para fumar: pipa, tabaquera, mechero, papel de fumar, paquete de tabaco picado.
- Cubiertos para alimentación: cuchara y tenedor de metal. Excepcionalmente, también se han documentado en los bolsillos de algunas víctimas (Fosa 128) cacahuetes con cáscara, y también semillas de uva al cribar el sedimento documentado en la cavidad abdominal (individuo ${ }^{\circ} 24$ Fosa 112).

- Otros: Lápiz de carpintero, tapón de neumático de vehículo.

\section{Útiles de farmacopea y cuidado personal (fig. 7)}

La materialidad recuperada en las fosas también refleja las prácticas del aseo cotidiano y la difícil vida carcelaria de la posguerra. En este sentido se han identificado objetos como pastilleros, frascos y botellas de medicamentos, así como alguna lendrera, cabestrillo, faja lumbar, bragueros de hernia inguinal, dentadura o dientes/puentes de oro. También se distinguen objetos de aseo personal como peines, horquilla de pelo, cepillo de dientes, pasta de dientes o espejo de mano. Estos repertorios nos permiten una relectura de las víctimas incidiendo en el cuerpo, la salud y la higiene personal desde un enfoque de análisis antropológico social y cultural muy enriquecedor.

\section{Útiles de escritura y elaboración de documentos}

Se trata de objetos como lápices, sacapuntas, plumillas, fragmentos de goma de borrar y extensores de lápiz. Estos repertorios nos permiten abordar la amplia esfera de la cultura y la educación, pues la lectoescritura se asocia a la capacidad de leer y escribir y por tanto a la alfabetización. Los testimonios orales confirman que aquéllos que sabían escribir, transcribían, leían o enseñaban en prisión a los que eran analfabetos. De manera que la documentación de lápices y minas de grafito evidencian que la escritura y/o el dibujo eran una práctica habitual.

\section{Objetos de culto}

Otras evidencias materiales que identifican prácticas personales son los elementos de la religión católica que se documentan. Por lo general, aparecen algunas medallas, escapularios, rosarios, alianzas de boda... Estos repertorios materiales nos ofrecen información sobre la religiosidad, el culto y la fe de algunas víctimas y confirman el amplio espectro de las víctimas, refutando el reduccionismo franquista que tildaba a todos los republicanos de anticlericales y contrarios a la fe cristiana y la religión. 


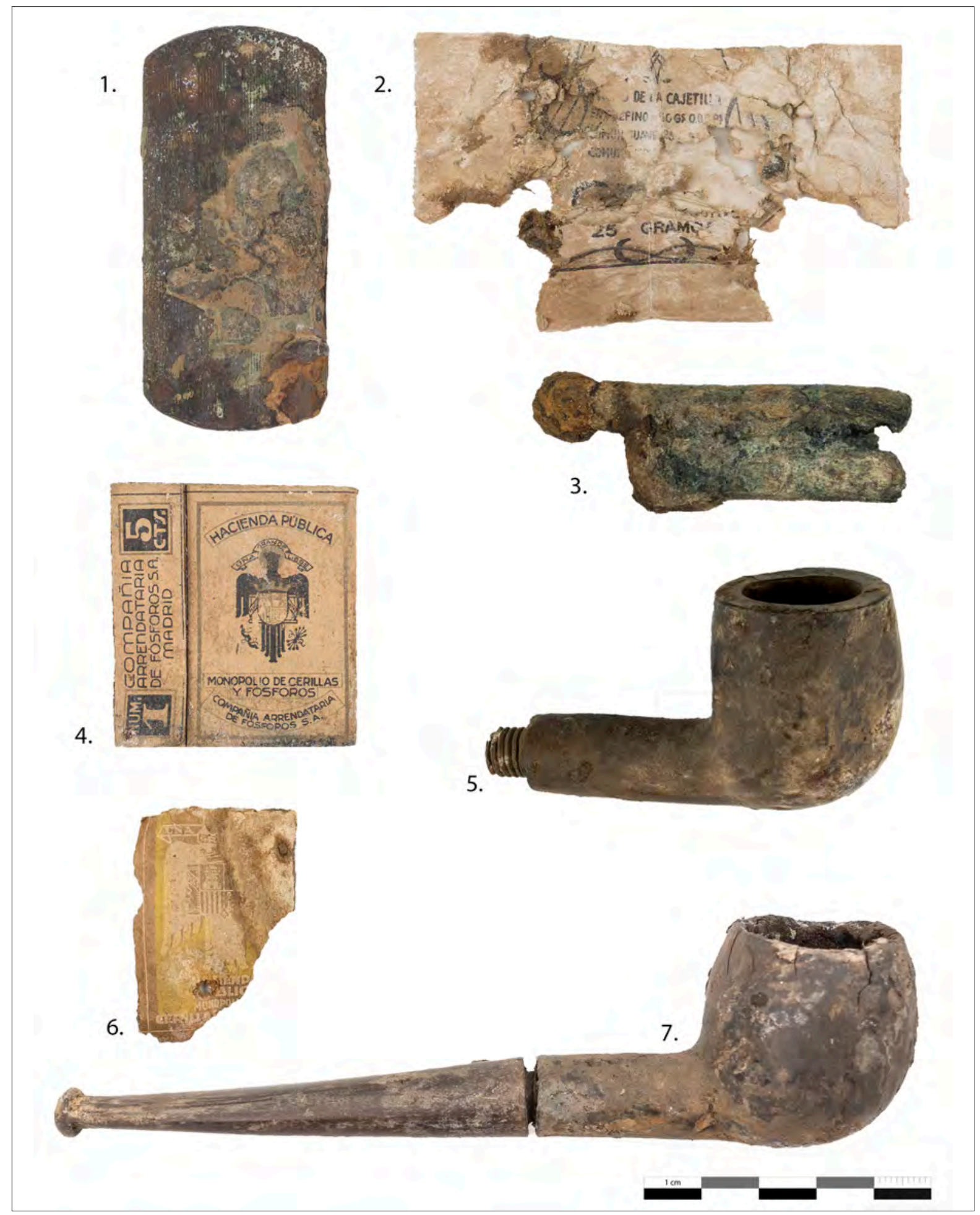

Fig. 6: Selección de objetos para fumar documentados junto con las víctimas en distintas fosas: 1. Mechero F.115; 2.Envoltorio de tabaco picado F.112; 3. Chisquero F.112; 4. Caja de cerillas F.128; 5. Pipa de fumar F.112; 6. Caja de cerillas F.112; 7. Pipa F.112. Fotografías: Eloy Ariza-ArqueoAntro. 


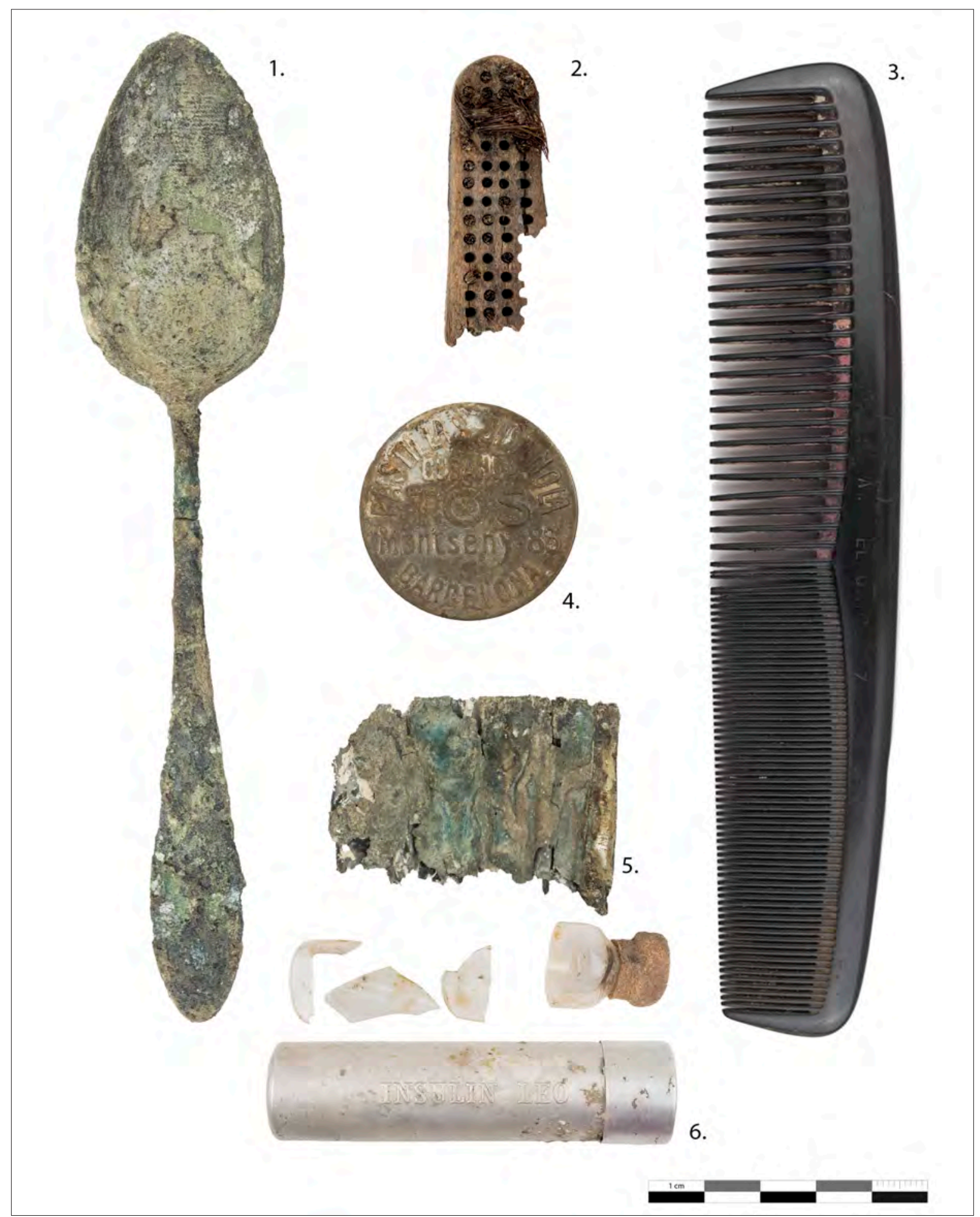

Fig. 7: Selección de útiles de farmacopea y aseo personal, documentados en las fosas: 1. Cuchara F.115; 2. Fragmento de cepillo de dientes F.112; 3. Peine F.115; 4. Pastillero F.112; 5. Fragmento de tubo de pasta dentífrica F.112; 6. Bote y ampolla de insulina F115. Fotografías: Eloy Ariza-ArqueoAntro. 


\section{Juego/Ocio}

Aunque con menor presencia, también se identifican entre los objetos exhumados alguna ficha de dominó, dados, recorte de sopa de letras, que son prueba de algunas aficiones que las víctimas llevaban cabo en la cárcel y muestran tanto las prácticas de socialización en prisión como, muy probablemente, el ocio y el juego como válvula de escape ante la reclusión y la privación de libertad. Sin duda, este tipo de materialidad nos permite plantear relecturas de carácter social y cultural en el día a día de las víctimas ya que la cárcel se convierte en espacio social y escenario de la vida personal de los condenados durante su encierro.

\section{Documentación en papel}

Los documentos que se han recuperado ofrecen pequeñas pinceladas de información sobre la realidad socio-política de las víctimas y sus historias personales, y responden a dos tipos. Aquellos que son documentación oficial de distinta naturaleza (cartilla militar, pagarés, cartilla vacunación) y documentos de carácter personal, como notas manuscritas en pequeños recortes de papel o tarjetas postales donde la víctima aparece como destinatario (algunas conservan sellos y marcaje de censura) o como remitente (su documentación en la fosa implica que la víctima no la llegó a enviar).

\section{Dinero-elementos de curso legal}

También están presentes en el registro arqueológico de las fosas los billetes y monedas (de distintas etapas históricas: Alfonso XIII, República, Franquismo), los sellos postales y timbres fiscales franquistas vinculados a documentación, algunas fichas como la del frontón, de casino o de apuestas. No cabe duda de que estos objetos tienen interpretaciones sobre la vida social y económica de las víctimas, aunque también hay que plantear la posibilidad de que algunas de estas piezas se atesoraran durante la estancia en prisión como recuerdos o elementos personales a modo de amuletos.

\section{Objetos reutilizados}

La existencia de objetos y elementos reutilizados nos indica la escasez de enseres y materiales, como el papel que fue muy deficitario durante la posguerra. Además, el contexto carcelario en el que las víctimas tuvieron que malvivir es una de las causas que explica la multifunción que pudieron tener algunos enseres, como los periódicos o casi cualquier cosa que pudiera reciclarse para aprovecharse al máximo, como pequeñas láminas de hojalata que, pulidas, se convertían en buriles o punzones para elaborar artesanía.

En algunas fosas se han documentado, recipientes y frascos de cristal reutilizados para contener notas en papel para identificar a la persona (fig. 8). Aparecen en la fosa como objetos asociados a las víctimas, pero depositados por el enterrador, siendo una clara evidencia de que ya existía la intencionalidad de identificarlos y facilitar la posible recuperación de los cuerpos desde el mismo momento en que los habían asesinado e iban a ser sepultados en la fosa.

Reutilización de documentación y cualquier soporte en papel para escribir en el reverso.

Reutilización de hojas de periódico para usos diversos (papel higiénico, protección del pecho ante la humedad). Algunos recortes de periódico que incluyen la foto y la noticia completa podrían haber sido atesorados como recuerdo o elemento de interés personal.

\section{Artesanía carcelaria}

Se trata de objetos manufacturados por las propias víctimas durante su estancia en prisión. Los que se exhuman en las fosas, normalmente son de pequeño tamaño y se han diseñado reutilizando elementos y materiales cotidianos como los huesos de fruta (oliva, albaricoque) o piedras. Aunque, en prisión, también se elaboraban piezas más complejas y de mayor tamaño en los talleres de artes plásticas, siendo precisamente referentes en el sistema penitenciario de posguerra, los que se impartían en la cárcel Modelo de València y Sant Miquel dels Reis (Agramunt 2005: 113-ss). No hay duda que algunos objetos que se documentan son vehículo de la creación y expresión artística, pues son diseñados y creados manualmente y ex profeso; es el caso de los huesos de fruta tallados, colgantes artesanales, navajas de pequeño tamaño de elaboración artesanal a modo de buril para cortar y tallar. Estos objetos tienen varias funciones. Por un lado, sirvieron a quien los realizó para evadirse de la rutina de la cárcel y de la dura vida en prisión que los privaba de libertad. Por otro, algunos encarnan el recuerdo constante de los seres queridos que vivían también condenados fuera de aquella celda. Aferrarse a aquellos recuerdos era tanto vía de escape como elemento de fuerza y resistencia. Estos objetos fueron quizá un regalo, un recordatorio, pero también un potente mensaje dirigido a sus familias, pues como productos de la actividad manual de la víctima se convierten en una forma de expresión. 


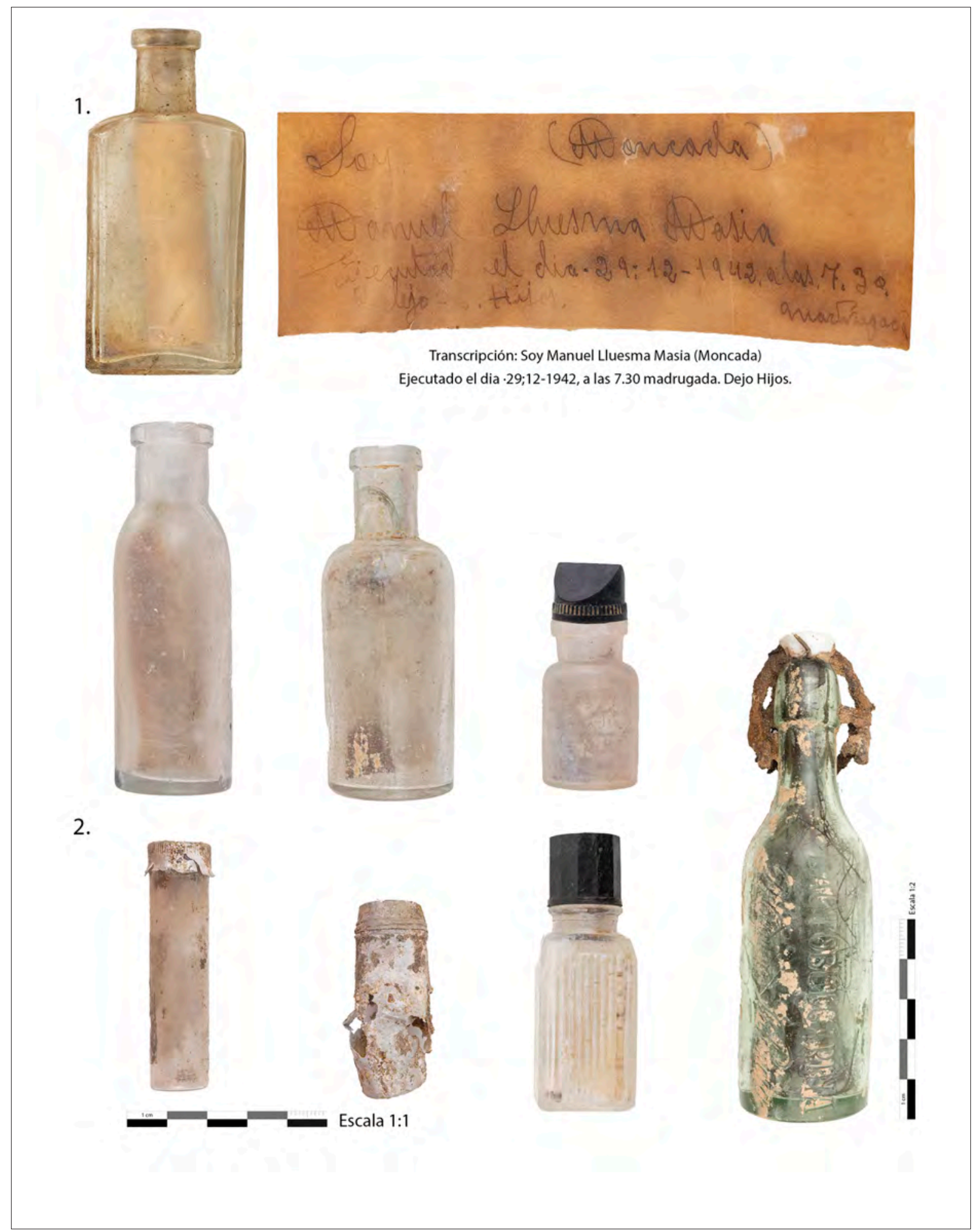

Fig. 8: 1.-Botella con nota manuscrita en su interior documentada en nicho 645. 2.- Conjunto de siete recipientes de distinta tipología documentados en la Fosa 120 junto con las víctimas. Fotografías: Eloy Ariza-ArqueoAntro. 
Con esta clasificación de objetos de las fosas de Paterna hemos intentado presentar de forma concisa la variada materialidad que es susceptible de ser documentada en los procesos de exhumación, con la intención de destacar su relevancia y la necesidad de estudio y divulgación. Estos objetos exhumados de las fosas comunes son albaceas de las historias de vida de las víctimas y han permanecido sepultados en las fosas junto a ellos. Pero a su vez, esta cultura material es transmisora de la memoria de un país y de las memorias de todos y todas. Los objetos humanizan los cuerpos y catalizan en la sociedad la importancia de la recuperación de las víctimas $\mathrm{y}$, en paralelo, sirven a las familias para encarnar los recuerdos y memorias de sus seres queridos. A nuestro modo de ver, estos objetos exhumados de las fosas junto a las víctimas del franquismo, además de ser objetos personales, tienen una lectura memorial y personal que nos describe cada una de esas historias y que los convierte en patrimonio y memoria de todas y todos.

\section{PERO ¿QUÉ HACEMOS CON LOS OBJETOS RECUPERADOS EN LOS PROCESOS DE EXHU- MACIÓN DE LAS FOSAS?}

Una vez exhumados esos objetos nos encontramos ante diferentes casuísticas:

Cuando la víctima ha podido ser identificada y la familia quiere recuperar tanto los restos mortales como aquellos objetos que en el proceso científico de excavación se han vinculado con dicha persona, en este caso, se entrega a los familiares el conjunto de restos humanos y objetos exhumados y es la familia la que decide qué hacer con ellos (Orden/PRE/2568/2011, III.E.1). En la mayoría de casos, los restos humanos y materiales son entregados en una misma caja de madera/resina, denominada caja de reducción, y suelen reinhumarse conjuntamente en el lugar que decide la familia. No obstante, cuando los objetos recuperados tienen cierta entidad o significado emocional para las familias, se convierten en piezas que ellos custodian en sus casas como memoria y herencia familiar, ya que a menudo estos materiales (pipas, anillos, colgantes, botones, a veces un puñadito de la tierra extraída de la fosa) son uno de los pocos recuerdos materiales que tienen de sus seres queridos.

Si no se ha podido identificar a la víctima, el cuerpo se inhuma en el cementerio de la población donde se halla la fosa, de manera individualizada e identificada de modo que permita su localización en futuras exhumaciones. En estos casos el protocolo de actuación apunta "junto con los efectos personales que hayan sido hallados" (Orden/PRE/2568/2011, III.E.2), es decir, que el individuo (cuya identidad no se ha podido concretar) y los objetos a él asociados en el proceso de exhumación se reinhuman conjuntamente.

Cuando el proceso de excavación arqueológica ha documentado objetos que no han podido asociarse a ningún individuo o no han sido reclamados por nadie, en este caso se aplica también el procedimiento III.E.2 del protocolo de exhumaciones (Orden PRE/2568/2011), se vuelven a inhumar en el cementerio de la población donde se halla la fosa junto con los restos antropológicos que no han podido ser identificados.

Dada la naturaleza de este tipo de exhumaciones, que pretenden reparar a las víctimas y a sus familiares, es evidente que al tratarse de objetos personales que pueden ser asociados a individuos y a familias identificables en la actualidad, son ellas quienes en primera instancia tienen a capacidad de obrar y decidir. Sin embargo, dichos objetos tienen la potencialidad de ser mucho más que un recuerdo con valor emocional y personal. Son, además, piezas con un significado relevante para la memoria contemporánea al ser una cultura material que nos habla de nuestro pasado reciente, de la violencia de estado y de la represión. Pero también del duelo, de los procesos de trasmisión de la memoria, del miedo, del silencio, de la desmemoria e incluso de la vida y la identidad de esas personas. Y por tanto nos ofrecen unos escenarios muy interesantes para el análisis histórico y también el antropológico desde un punto de vista social y cultural.

Quizás deberíamos de valorar y asumir la necesidad de generar repertorios patrimoniales del pasado reciente con el objetivo de poder nutrir futuros museos y con la finalidad de poder ofrecer discursos y relecturas que aúnen la reparación judicial, social e historiográfica de las víctimas y que permitan la justicia y la verdad en los discursos y en la memoria pública.

Por otro lado, sin apertura de procedimiento judicial, los objetos recuperados en las exhumaciones dejan de ser pruebas en un caso de investigación, y su función como evidencias de interés criminalístico se difumina pues no hay delito/crimen que juzgar. La exhumación requiere una intervención forense con metodología arqueo-antropológica y aunque debería llevar aparejado un procedimiento judicial para el esclarecimiento de los crímenes, en el Estado español no ocurre así (Pego 2020). 
Lo que sí ocurre es que al tratarse de restos que se localizan en el subsuelo, la exhumación queda supeditada a la implementación de métodos y técnicas de la disciplina arqueológica. Y, por tanto, se deben cumplir los requisitos que la legislación establece en cuanto a actuaciones arqueológicas (obtención de permisos, plazos, registro de materiales, elaboración de informes y memorias, etc.) de conformidad con el Decreto 107/2017 del Consell, por el que se aprueba el Reglamento de Regulación de las Actuaciones Arqueológicas en la Comunitat Valenciana. Sin embargo, no se les aplica la legislación patrimonial vigente para objetos recuperados en actuaciones arqueológicas, la cual indica que deben ser custodiados y depositados en museos o instituciones públicas competentes de la salvaguarda, el estudio y la divulgación de la cultura material arqueológica.

Las fosas y los cuerpos y objetos que en ellas se documentan, están flotando en un limbo en lo que respecta al ámbito judicial y también al patrimonial. Y si bien es cierto que desde 2011 se han protocolizado las exhumaciones con la intención principalmente de estructurar y planificar las excavaciones y la metodología, estos protocolos forenses no concretan algunos temas esenciales en lo que respecta al régimen jurídico de los cuerpos (Montero 2010) ni tampoco sobre los objetos a ellos asociados (Jiménez y Herrasti 2017).

Si leemos la Ley de Memoria Valenciana, en ella se habla de Espacios y Lugares de Memoria (artículo 20.1) como aquellos espacios, inmuebles o parajes del territorio valenciano que revelen interés por haberse desarrollado en ellos hechos de singular relevancia por su significación histórica, simbólica o por su repercusión en la memoria colectiva de la lucha de los valencianos y valencianas por sus derechos y libertades democráticas desde la proclamación de la II República Española hasta la entrada en vigor del Estatuto de Autonomía (a tenor de lo cual, reiteramos, de nuevo, la singularidad y significación de El Terrer y el cementerio de Paterna). También se definen los Itinerarios de Memoria (art. 20.2) formados por dos o más lugares de la memoria democrática de la Comunitat Valenciana que coincidan en el espacio y tengan criterios interpretativos comunes de carácter histórico o simbólico, sin perjuicio de que concurran otros valores relevantes de carácter arquitectónico, paisajístico o de tipo ambiental, etnográfico o antropológico. Además, en el Título III sobre el derecho a la memoria, la ley también regula la protección y conservación del patrimonio documental, bibliográfico e inmaterial. Del mismo modo, también se reconoce explícitamente algunos elementos materiales de nuestro pasado reciente como patrimonio y se protegen las construcciones civiles y militares de la Guerra Civil de conformidad con la ley 9/2017, de 7 de abril, de la Generalitat, que modifica la Ley 4/1998, del patrimonio cultural valenciano. Estos vestigios arqueológicos se consideran una herramienta fundamental de recuperación de los acontecimientos del pasado para las generaciones futuras, que podrán tener una aproximación más fidedigna a los hechos, a partir de estos testimonios patrimoniales de nuestra historia más reciente.

Sin embargo, no existe mención alguna a la cultura material que se exhuma de las fosas. El debate está en si son vestigios arqueológicos y un patrimonio material relevante por su significación histórica, simbólica o por su repercusión en la memoria colectiva o no. En este sentido, nosotros abogamos por abordar este debate desde un punto de vista teórico y conceptual, pues en este marco bien podríamos denominar a este patrimonio mueble asociado a las exhumaciones como Objetos de Memoria. El argumento es sencillo, pues como recoge la Ley de Memoria Valenciana, la Organización de Naciones Unidas en la Resolución 2.004/72 de la Comisión de Derechos Humanos (E/CN.4/2005/102/Add.1), señala, dentro de las obligaciones de los estados, la adopción de medidas eficaces para luchar contra la impunidad, la garantía del derecho inalienable a la verdad, el deber de recordar y el derecho al saber. El principio $3 .^{\circ}$ sobre el deber de recordar proclama: El conocimiento por un pueblo de la historia de su opresión forma parte de su patrimonio y, por ello, se debe conservar adoptando medidas adecuadas en aras del deber de recordar que incumbe al Estado para preservar los archivos y otras pruebas relativas a violaciones de los derechos humanos y el derecho humanitario y para facilitar el conocimiento de tales violaciones. Esas medidas deben estar encaminadas a preservar del olvido la memoria colectiva y, en particular, a evitar que surjan tesis revisionistas y negacionistas.

No hay duda que los objetos ofrecen unas narrativas sobre el pasado traumático en clave familiar que puede extrapolarse al conjunto de la sociedad. Demos, pues, la opción a que las familias valoren si quieren conservar esos objetos o si quieren donarlos a museos públicos para que con la recuperación de la historia y la memoria de sus familiares se explique y se divulgue la memoria y la historia de todos. Pues la invisibilidad absoluta de esa materialidad y su circunscripción exclusivo al ámbito privado 
dificulta su gestión, conservación y difusión como elementos claves para la construcción y la divulgación de una memoria pública de nuestro pasado reciente. De manera que después de una década de exhumaciones científicas en territorio valenciano, quizás sea necesario plantear un debate profesional sobre esta cultura material que nos permita abordar desde la arqueología las prácticas socio-políticas y culturales vinculadas a las políticas de violencia, purga y represión del Estado franquista. Quizás debería evaluarse la necesidad de que se establezcan ex novo protocolos de custodia conservación y divulgación de esta cultura material exhumada a partir de la modificación y actualización del marco legislativo vigente. Pues hasta la fecha, las lagunas en la legislación hacen difícil su custodia, conservación y puesta en valor. En este sentido, abogamos porque se de opción siempre a las familias a poder elegir en primer lugar, pero que ante situaciones de no identificación o de renuncia sea la administración la que asuma la custodia y estos materiales sean depositados en instituciones y museos públicos, ya que su reinhumación anula la posibilidad de un uso científico, museográfico y público de estos objetos.

\section{REFLEXIÓN FINAL: EL RETO DE GESTIONAR, CONSERVAR Y DIFUNDIR LA MEMORIA}

Es un gran reto poder asumir la preservación de unos objetos contemporáneos, normalmente de uso cotidiano, que fabricados con materiales muy variados no responden a la tipología tradicional de objeto arqueológico. Es decir, no están hechos ni de cerámica ni de piedra ni de metales que tras cientos o miles de años han consolidado sus procesos corrosivos. Al contrario, nos encontramos objetos de materiales contemporáneos diversos, cuyo proceso de degradación no ha cumplido un siglo y, por tanto, su extracción del subsuelo con los procesos de exhumación altera su naturaleza de manera feroz. De manera que, no tiene ningún sentido recuperar pantalones, zapatos, camisas, cinturones, botones, hebillas, lápices, cucharas, pipas, carteras anillos y un largo etcétera de objetos personales y cotidianos, si una vez exhumados no son sometidos a procesos científicos y profesionales de limpieza, documentación, inventario, catalogación, consolidación preventiva y restauración. Por el contrario, almacenar estas piezas en cajas y bolsas de plástico durante meses para posteriormente entregarlas, en el mejor de los casos, después de una limpieza o consolidación preliminar a los familiares parece un sin sentido, a no ser que su finalidad sea estrictamente la reinhumación, que es lo que ha sucedido hasta la fecha.

Por otro lado, asumida la necesidad de gestión, y del mismo modo que las administraciones públicas ofrecen subvenciones o asumen de oficio el gasto en los procesos de exhumación de las víctimas, se debería contemplar la necesidad de que asuman también los gastos de estudio, limpieza, consolidación preventiva, restauración, documentación, así como la divulgación posterior de los restos materiales arqueológicos exhumados en estos procedimientos científicos. Del mismo modo debería suceder con los estudios antropológicos sociales, etnográficos y documentales que abordan desde el presente y desde los vivos estos procesos que la exhumación arqueológica excava, y que en territorio valenciano son anecdóticos (García y Gadea 2020).

En el protocolo de actuación en exhumaciones de víctimas de la guerra civil y la dictadura (Orden PRE/2568/2011) se considera que la apertura de una fosa es una tarea interdisciplinar y se cita expresamente la intervención de tres tipos de especialistas: historiadores, arqueólogos y especialistas forenses. Quizás si se entendiera la exhumación como un procedimiento transversal con lecturas multidisciplinares e intergeneracionales se advertiría lo enriquecedor que sería que profesionales de la antropología, la conservación-restauración, la documentación fotográfica y audiovisual, sociología y la divulgación también fueran de presencia obligatoria en estos procedimientos. Porque la memoria va más allá de exhumar, y no entenderla así supone un reduccionismo simplista que nos hace desaprovechar oportunidades de implementar políticas públicas de memoria integrales.

Recientemente, en 2020 y a propósito de la exhumación de la fosa $\mathrm{n}^{\circ} 128$, el equipo técnico de ArqueoAntro planteó a la Delegación de Memoria de la Diputación de Valencia, que subvencionaba el proceso, la necesidad de valorar la recuperación, puesta en valor y preservación de, al menos, una selección de las más de los 25 conjuntos de indumentaria y materiales exhumados en esta fosa, dado su excepcionalidad. La propuesta técnica de ArqueoAntro fue valorada positivamente por el área de Memoria de la Diputación que junto con el Museu Valencià d'Etnologia (L'Etno), están evaluando las necesidades y posibilidades para que estos materiales exhumados puedan conservarse y 
custodiarse en el museo con fines memorialísticos públicos. Precisamente, el equipo de ArqueoAntro ya colaboró con L'Etno para incluir en su exposición Prietas las Filas: Vida Cotidiana y Franquismo de 2018, una pequeña selección de objetos exhumados de la fosa 113 del cementerio de Paterna, que fueron expuestos en sala durante los 12 meses que fue visitable la exposición (Moreno y Candela 2018: 65-ss).

En este sentido, reiteramos nuestra propuesta y defendemos que el estudio de los cuerpos y los objetos exhumados nos debe servir para analizar y conocer las microhistorias personales de cada víctima, pero también para ofrecer al conjunto de la ciudadanía relatos que deconstruyan la hegemonía de la memoria heredada. No cabe duda que los cuerpos y objetos que las metodologías arqueológica y antropológica consiguen recuperar en los procesos de exhumación, devienen -siguiendo las tesis de W. Benjamin (2003) - evidencias clave para hacer historia a contrapelo, para ofrecer discursos desde la perspectiva de los vencidos y desde la marginalidad que los discursos hegemónicos habían sepultado. Recuperar la memoria desde la interdisciplinaridad es necesario para dar voz los olvidados de la historia y para alumbrar el presente desde la memoria de las víctimas del pasado (Mate 2006).

La arqueología y la memoria deben ser públicas y sociales y fomentar la participación y la convivencia a partir del análisis y la divulgación de los problemas que afectan a la sociedad actual, anclándose siempre en la ciencia, pues solo así conseguiremos que a través de la multidisciplinaridad y de las políticas públicas de memoria se contribuya además de a la reparación, la justicia y la verdad, al crecimiento cívico, moral y reflexivo a través del conocimiento y la divulgación de nuestro pasado reciente.

\section{NOTAS}

1. En 2019, la Diputación de Valencia, a través del Área de Memoria Histórica, creó una comisión de trabajo "para recuperar la memoria de los fusilados en el Paredón de España" en la que también participan el Ayuntamiento de Paterna, la Agrupación de Familias de Víctimas del Paredón de España, el Grupo para la Memoria Histórica de València y la empresa Barrio La Pinada, propietaria de los terrenos. El objetivo es la construcción de un memorial en honor de las víctimas asesinadas allí y sepultadas en el cementerio de Paterna. No obstante, hasta la fecha aún no se ha materializado. <https://www.dival.es/es/sala-prensa/ content/la-diputacio-crea-una-comision-de-trabajo-para-recuperar-la-memoria-de-los-fusilados-en-el-p > .
2. Según la información demográfica que conserva el archivo municipal del municipio, Paterna en la década de 1930 contaba con una población de 6284 habitantes, que creció a 7885 en 1940 y alcanzó los 9736 habitantes en 1950. Si tomamos estos datos como referencia y los comparamos con las cifras de muertes violentas, causa de la represión en El Terrer, la magnitud de los asesinatos escapa a cualquier duda. En este sentido, las fosas del cementerio municipal albergaron una cantidad de personas que si se computan de manera acumulativa equivaldría al $28 \%$ de la población local en los años 1940. Las 2237 personas asesinadas en Paterna suponen el $47 \%$ del total de fusilados del territorio valenciano (Gabarda 2007).

3. Cabe mencionar que, en el caso del cementerio de Paterna, el registro cementerial de la época, que se conservaba hasta época de la Transición, desapareció y hoy sólo es consultable únicamente alguna información parcial que las familias han ido aportando desde entonces. Por otro lado, se produjeron vaciados de fosas y traslados al Valle de los Caídos durante la dictadura (según la información del Mapa de Fosas Estatal al menos en el año 1959) que también generan vacíos de información.

4. En este sentido, sus cuerpos también tuvieron un trato diferenciado en su acceso al camposanto. El cementerio se circunda perimetralmente con un muro de mampostería y el acceso principal al camposanto se hace por una puerta principal que recae en la fachada del recinto (fig. 1). Sin embargo, según cuentan los testimonios orales, los cuerpos ya sin vida de los ejecutados en El Terrer eran introducidos en el cementerio, destino a las fosas, por una pequeña puerta lateral del cuadrante 2 .

5. Leoncio Badía Navarro (1907-1987) era republicano y fue condenado a trabajar como sepulturero en el cementerio de Paterna entre 1939 y 1945 para "enterrar a los suyos". Leoncio es reconocido por su humanidad y buen hacer durante los años que fue enterrador pues, siempre que pudo y a escondidas: colocó botellas con notas de papel que identificaban a la víctima; entregó a las viudas y huérfanos de las víctimas retales de la ropa que él mismo recortó de la indumentaria que llevaban los muertos antes de enterrarlos en la fosa; incluso, en alguna ocasión, mostró a la familia el cuerpo al amparo de la noche (Gabarda et al. 2019: 64).

6. Es cierto que, como apunta González-Ruibal, en el caso de los asesinatos políticos masivos, hablamos no solo de recuperar las identidades individuales de las víctimas sino también la importancia de recuperar desde la arqueología las identidades colectivas que fueron desubjetivadas y cosificadas (2020: 9-10).

7. Además de los objetos exhumados, también contamos con objetos de las víctimas que conservan las familias bien porque fueron recuperados en caliente a pie de fosa (fragmentos de indumentaria, objetos personales) o bien porque las familias pudieron preservarlos como último y, a menudo, único recordatorio de la víctima (fotografía, abalorios, enseres personales, cartas). 


\section{BIBLIOGRAFÍA}

AGRAMUNT, F. (2005): Arte y represión en la guerra civil española. Artistas en checas, cárceles y campos de concentración, Valladolid.

BABY, S.; NÉRARD, F. X. (2017): Objects from the missing. Exhumations and uses of the material traces of mass violence, Les Cahiers Sirice 19 (2), 5-20. DOI: https://doi.org/10.3917/lcsi.019.0005

BENJAMIN, W. (2003): La obra de arte en la época de su reproductibilidad técnica, México.

BLAU, S.; SKINNER, M. (2005): The use of forensic archaeology in the investigation of human rights abuse: Unearthing the past in East Timor, The International Journal of Human Rights 9 (4), 449-463. DOI: https://doi.org/10.1080/13642980500349857

BUCHLI, V.; LUCAS, G. (eds.) (2001): Archaeologies of the contemporary past, Londres-Nueva York. DOI: https://doi.org/10.4324/9780203185100

CASAS, J. D. D.; SANTIAGO, A.; RODRÍGUEZ, M. S.; ALBARRÁN, M. E. (2006): Fenómenos de conservación cadavérica. Saponificación, Revista de la Escuela de Medicina Legal 3, 27-36.

CRIADO, F. (2010): Què és avui 1'Arqueologia, Cota Zero: revista d'arqueologia i ciència 25, 51-56.

CROSSLAND, Z. (2000): Buried Lives: Forensic Archaeology and the Disappeared in Argentina, Archaeological Dialogues 7 (2), 146-159. DOI: https://doi.org/10.1017/S1380203800001707

DÍAZ-RAMONEDA, E.; VILA, A.; SANCHO, S.; CALPE, A.; IGLESIAS-BEXIGA, J.; MEZQUIDA, M. (e.p.): Les fosses de Paterna, testimonis de la maquinària repressiva del règim franquista al País Valencià, RAP 31.

ETXEBERRIA, F.; SERRULLA, F. (2019): El caso de los cerebros de Pedraja. Ciencias forenses y memoria histórica en España, Mètode: Revista de difusión de la Investigación 2 (101), 82-91.

FERNÁNDEZ, V. M. (2006): Una arqueología crítica. Ciencia, Ética y Política en la construcción del pasado, Barcelona.

FERRÁNDIZ, F. (2006): The Return of Civil War Ghosts: The Ethnography of Exhumations in Contemporary Spain, Anthropology Today 22 (3), 7-12. DOI: https://doi.org/10.1111/j.1467-8322.2006.00437.x

FERRÁNDIZ, F. (2007): Exhumaciones y políticas de la memoria en la España contemporánea, Hispania Nova. Revista de Historia Contemporánea 7.

FERRÁNDIZ, F. (2009): Fosas comunes, paisajes del terror, $R e$ vista de Dialectología y Tradiciones Populares LXIV, 61-94.

DOI: https://doi.org/10.3989/rdtp.2009.029

FERRÁNDIZ, F. (2011): Autopsia social de un subtierro, Isegoría. Revista de Filosofía Moral y Política 45, 525-544. DOI: https://doi.org/10.3989/isegoria.2011.i45.741
FERRÁNDIZ, F. (2014): El pasado bajo tierra. Exhumaciones contemporáneas de la Guerra Civil, Barcelona.

FERRÁNDIZ, F. (2020): Etnografías contemporáneas: anclajes, métodos y claves para el futuro, Barcelona.

FORTUNA, M.; MEZQUIDA, M.; MARTÍNEZ,A. (2017): Enterramientos de soldados exhumados en el Frente de Levante, CSIC.

GABARDA, V. (2007): Els afusellaments al País Valencià (19381956), València.

GABARDA, V. (2020a): El cost humà de la repressió al País Valencià (1936-1956), València.

GABARDA, V. (2020b): El cementeri de Paterna con a exemple de monumentalització popular, Postguerres/Aftermaths of war (T. Abelló, G. C. Cattini, V. Gavin, J. Ibarz, C. Santacana, O. Solé, A. Vives, coords.), Barcelona, 169-187.

GABARDA, V. (dir.) (2021): Violencia, conceptualización, memoria, represión, estudios, monumentalización, exhumaciones, Valencia, 1936-2020, València.

GABARDA, V.; MEZQUIDA, M.; IGLESIAS, J.; CALPE, A.; LÓPEZ, G.; ARIZA, E. (2019): La memòria en un racó, Manises.

GARCIA-HERNANDORENA, M. J.; GADEA i PEIRÓ, I. (2020): Etnografia d'una exhumació. El cas de la fossa 100 del cementeri de Paterna, València.

GASSIOT, E. (2008): Arqueología de un silencio. Arqueología forense de la Guerra Civil y del Franquismo, Complutum 19 (2), 119-130.

GONZÁlEZ-RUIBAL, A. (2007): Making Things Public: Archaeologies of the Spanish Civil War, Public Archaeology 6 (4), 203-226.

DOI: https://doi.org/10.1179/175355307X264165

GONZÁLEZ-RUIBAL, A. (2008). Arqueología de la Guerra Civil Española, Complutum 19 (2), 11-20.

GONZÁLEZ-RUIBAL, A. (2012). From the battlefield to the labour camp: archaeology of civil war and dictatorship in Spain, Antiquity 86, 456-473.

DOI: https://doi.org/10.1017/S0003598X00062876

GONZÁLEZ-RUIBAL, A. (2019): An Archaeology of the contemporary era, Abingdon.

DOI: https://doi.org/10.4324/9780429441752

GONZÁLEZ-RUIBAL, A.; AYÁN, X. (2018): Arqueología. Una introducción al estudio de la materialidad del pasado, Madrid.

GONZÁLEZ-RUIBAL, A.; MOSHENSKA, G. (eds.) (2015): Ethics and the Archaeology of Violence, New York. DOI: https://doi.org/10.1007/978-1-4939-1643-6

GOULD, R. A. (2007). Disaster Archaeology, Salt Lake City.

HAGLUND, W. D.; CONNOR, M.; SCOTT, D. D. (2001): The Archaeology of Contemporary Mass Graves, Historical Archaeology 35 (1), 57-69. DOI: https://doi.org/10.1007/BF03374527

HALLAM, E.; HOCKEY, J. (2001): Death, Memory and Material Culture, Oxford. 
HAMILAKIS, Y. (2011): Archaeological ethnography: A multitemporal meeting ground for archaeology and anthropology, Annual Review of Antropology 40, 399-414.

DOI: https://doi.org/10.1146/annurev-anthro-081309-145732

HARRIS, O.; CIPOLLA, C. (2017): Archaeological Theory in the new Millenium: Introducing Current Perspectives, London $\&$ New York.

DOI: https://doi.org/10.4324/9781315713250

HARRISON, R.; SCHOFIELD, J. (2010): After modernity. Archaeological approaches to the contemporary past, Oxford. DOI: https://doi.org/10.1093/oso/9780199548071.001.0001

HAZAN, P. (2008): Les dilemmes de la justice transitionnelle, Mouvements 53, 41-47.

DOI: https://doi.org/10.3917/mouv.053.0041

HIRSCH, M. (2015). La generación de la posmemoria. Escritura y cultura visual después del Holocausto, Madrid.

HIRSCH, M.; SPITZER, L. (2006): Testimonial Objects: Memory, Gender, and Transmission. Poetics Today 27 (2), 353-383. DOI: https://doi.org/10.1215/03335372-2005-008

HODDER, I. (ed.) (2012a): Archaeological theory today, Cambridge. HODDER, I. (ed.) (2012b): Entangled. An archaeology of the relationships between humans and things, Oxford. DOI: https://doi.org/10.1002/9781118241912

IGLESIAS, J.; BENITO, M.; CALPE, A.; FORTUNA, M.; MARTÍNEZ, A.; MEZQUIDA, M. (2018): Proceso de exhumación, cadena de custodia e identificación de los cuerpos. Aspectos técnicos y jurídicos. Antropología forense durante los trabajos en el Cementerio Municipal de Paterna, Actas I Jornades de Memòria Democràtica a Paterna, València, 131-145.

ITURRIAGA, N. (2019): At the Foot of the Grave: Challenging Collective Memories of Violence in Post-Franco Spain, Socius: Sociological Research for a Dynamic World 5, 1-16. DOI: https://doi.org/10.1177/2378023119832135

JIMÉNEZ, J.; HERRASTI, L. (2017): Objets associés des fosses de la guerre civile en Espagne, Les Cahiers Sirice 19, 41-54. DOI: https://doi.org/10.3917/lcsi.019.0041

JOHNSON, M. (2000): Teoría arqueológica. Una introducción, Barcelona.

MATE, M. R. (2006): Medianoche en la historia. Comentarios a las tesis de Walter Benjamin, Madrid.

MATE, M. R. (2011): Justicia: autores y temas para una nueva aproximación, Justicia y memoria. Hacia una teoría de la justicia anamnética (J.A. Zamora, M. R. Mate Eds.), Barcelona, 5-8.

MEJÍAS, F. (2020): Arqueología de la represión, entre el silencio y la memoria: las fosas comunes del campo de concentración de Albatera (San Isidro, Alicante), Ebre 38 10, 69-123.

MEZQUIDA, M. (2013): Arqueología de la Guerra Civil. Una arqueología por asimilar, La Linde 1, 42-50.

MEZQUIDA, M. (2017): Excavaciones y exhumaciones de fosas de la guerra civil y del franquismo en el País Valenciano, $\mathrm{La}$ Linde 8, 167-218.
MEZQUIDA, M.; CALPE, A. (2021): El Paredón de Paterna: Una deuda con uno de los espacios de memoria más significativos del País Valenciano, Violencia, conceptualización, memoria, represión, estudios, monumentalización, exhumaciones, Valencia, 1936-2020 (V. Gabarda, coord.), València, 213-234.

MEZQUIDA, M.; IGLESIAS, J.; CALPE, A.; MARTÍNEZ, A. (2021): Procesos de investigación, localización, excavación, exhumación e identificación de víctimas de la Guerra Civil y del Franquismo en el Levante peninsular, Violencia, conceptualización, memoria, represión, estudios, monumentalización, exhumaciones, Valencia, 1936-2020 (V. Gabarda Coord.), València, 295-314.

MEZQUIDA, M.; MARTÍNEZ, A.; CALPE, A.; BENITO, M.; IGLESIAS, J.; FORTUNA, M. (2018): Procesos de Excavación y Exhumación en el Cementerio Municipal de Paterna, Actas de I Jornades de Memòria Democràtica a Paterna, València, 146-156.

MONTERO, J. (2010): Exhumando el legado material de la represión franquista: De la percepción social a la encrucijada jurídica y patrimonial, Recorriendo la Memoria (J. Almansa, ed.), Oxford, 67-82.

MORENO, A. (e.p.): La corbata de José, Objectes (des)apareguts (M. A. Gomar, ed.), València.

MORENO, A.; CANDELA, J. M. (2018): Prietas las Filas, Vida Codiana y franquismo, València.

MORENO, A.; MEZQUIDA, M.; SCHWAB, M. E. (2021): Exhumaciones de fosas comunes en el País Valenciano: 10 años de intervenciones científicas, Ebre 38: revista internacional de la Guerra Civil, 1936-1939 11, 125-152.

MORENO,A.; SAPENA, T. (2017): Refugis antiaeris: patrimoni de la Guerra Civil a la ciutat de València, DEBATS. Revista de cultura, poder i societat 131/2, 123-140.

DOI: https://doi.org/10.28939/iam.debats.131-2.10

MUÑOZ-ENCINAR, L. (2019): Unearthing gendered repression: an analysis of the violence suffered by women during the civil war and Franco's dictatorship in Southwestern Spain, World Archaeology 51 (2), 759-777.

DOI: https://doi.org/10.1080/00438243.2020.1740775

MUÑOZ-ENCINAR, L.; AYÁN, X; LÓPEZ, A. (2013): De la ocultación de las fosas a las exhumaciones. La represión franquista en el entorno del Campo de Concentración de Castuera, Castuera.

OLSEN, B. (2010): In defense of things. Archaeology and the ontology of objects, Lanham.

OLSEN, B.; SHANKS, M.; WEBMOOR, T.; WITMORE, C. (2012): Archaeology. The discipline of things, Berkeley. DOI: https://doi.org/10.1525/9780520954007

OLSEN, B.; WITMORE, C. (2015): Archaeology, symmetry and the ontology of things. A response to critics, Archaeological Dialogues 22, 187-197.

DOI: https://doi.org/10.1017/S1380203815000240 
PEGO, L. (2020): Naciones Unidas. El estado de la cuestión de las fosas de personas desaparecidas en la Guerra Civil y la Dictadura franquista en la España actual, Las exhumaciones de la Guerra Civil y la dictadura franquista 2000-2019. Estado actual y recomendaciones de futuro (F. Etxeberria, coord.), 107-126.

POLO, M.; GARCÍA-PRÓSPER, E.; CRUZ, E.; RUIZ, H. (2012): Fosas comunes exhumadas en el territorio de la agrupación guerrillera de Levante y Aragón (2005-2011), Boletín Galego de Medicina Legal e Forense 18, 99-116.

RAMOS , J. (2018): La arqueología de la Guerra Civil Española en Cataluña, Romula 17, 133-154.

RENSHAW, L. (2010): The Scientific and Affective Identification of Republican Civilian Victims from the Spanish Civil War, Journal of Material Culture 15: 4, 449-63. DOI: https://doi.org/10.1177/1359183510382961

RENSHAW, L. (2011): Exhuming Loss. Memory, Materiality and Mass Graves of the Spanish Civil War, Londres y NY.

RENSHAW, L. (2018): Thinking outside the grave. The material traces of Republican lives before the Spanish Civil War, Public Humanities and the Spanish Civil War. Connected and Contested Histories (A. Ribeiro de Menezes, A. Cazorla-Sánchez, A. Shubert eds.), Cham, 139-162. DOI: https://doi.org/10.1007/978-3-319-97274-9_7

ROBBEN, A. C. G. M. (2017): Death, Mouring and Burial: A cross-cultural reader, New York.

RODRIGO, J. (2008): Hasta la raíz: Violencia durante la Guerra Civil y la dictadura franquista, Madrid.

SANT-CASSIA, P. (2007): Bodies of Evidence: Burial, Memory and the Recovery of Missing Persons in Cyprus, New York-Oxford.

SANTONJA, J. L. (2021): Animetes Santes. Costums tradicionals valencians sobre el més enllà, València.

SCARRE, C.; SCARRE, G. (2006): The Ethics of Archaeology: Philosophical Perspectives on Archaeological Practice, Cambridge. DOI: https://doi.org/10.1017/CBO9780511817656

SCHOFIELD, J. (2005): Combat archaeology. Material culture and modern conflict, London.
SCHUTE, I. (2018): Collecting Artifacts on Holocaust Sites: A Critical review of Archaeological Research in Ybenheer, Westerbork and Sobibor, International Journal of Historical Archaeology 22 (3), 593-613. DOI: https://doi.org/10.1007/s10761-017-0437-y

SOLÉ, Q. (2019): Pervivencia de las fosas comunes de la guerra civil española en el siglo XXI. Evidencia cultural, particularidad académica, Historia Contemporánea 60 , 439-475. DOI: https://doi.org/10.1387/hc.20312

SOLÉ, Q.; GALLEGO, L. (eds.) (2020): Repressed bodies. Archaeology, memory, politics. Journal of Contemporary Archaeology 7 (2).

STOVER, E.; HAGLUND, W. D.; SAMUELS, M. (2003): Exhumation of Mass Graves in Iraq: Considerations for Forensic Investigations, Humanitarian Needs, and the Demands of Justice, Journal of the American Medical Association 290:5, 663-66.

DOI: https://doi.org/10.1001/jama.290.5.663

STURDY, C. (2015): Holocaust Archaeologies: Approaches and Future Directions, Nueva York.

THEUNE, C. (2010): Historical Archaeology in National Socialist Concentration Camps in Central Europe, Historische Archäologie 3, 1-14.

THEUNE, C. (2018): A Shadow of War. Archaeological Approaches to Uncovering the Darker Sides of Conflict from the 20th Century, Leiden.

VICENT, J. M. (2007): La arqueología a comienzos del siglo XXI. Ciencia, tecnología, valores y sociedad, Actas de las XII Jornadas de Estudios sobre Lanzarote y Fuerteventura (E. R. de León Arbelo, A. F. Martín, M.J. Alonso, coords.), Lanzarote 2: III, 325-347.

WAGNER, S. (2008): To Know Where He Lies: DNA Technology and the Search for Srebrenica's Missing, Berkeley. DOI: https://doi.org/10.1525/9780520942622

WEIL, S. (2007): Escritos históricos y políticos, Madrid.

ZAMORA, J. A.; MATE, M. R. (2011): Justicia y memoria. Hacia una teoría de la justicia anamnética, Barcelona. 